WORKING PAPER · NO. 2021-04

\title{
Updating the United States Government's Social Cost of Carbon
}

Tamma Carleton and Michael Greenstone JANUARY 2021 


\title{
Updating the United States Government's Social Cost of Carbon
}

\author{
Tamma Carleton \\ Bren School of Environmental Science \& Management \\ University of California, Santa Barbara \\ Michael Greenstone \\ Department of Economics \\ University of Chicago \\ NBER
}

\begin{abstract}
This paper outlines a two-step process to return the United States government's Social Cost of Carbon (SCC) to the frontier of economics and climate science. The first step is to implement the original 2009-2010 Inter-agency Working Group (IWG) framework using a discount rate of $2 \%$. This can be done immediately and will result in an SCC for 2020 of $\$ 125$. The second step is to reconvene a new IWG tasked with comprehensively updating the SCC over the course of several months that would involve the integration of multiple recent advances in economics and science. We detail these advances here and provide recommendations on their integration into a new SCC estimation framework.
\end{abstract}

We thank Jared Stolove for exceptional research assistance and Trevor Houser, Amir Jina, Robert Kopp, Ishan Nath, and Cass Sunstein for valuable critiques and suggestions. This working paper will also appear in a forthcoming book of energy and environmental policy proposals to be published by the Energy Policy Institute at the University of Chicago (EPIC). Contact information: tcarleton@ucsb.edu and mgreenst@uchicago.edu. 


\section{Heart of the Problem}

All over the world, climate policies have the potential to provide large benefits by reducing the harms that result from carbon dioxide $\left(\mathrm{CO}_{2}\right)$ emissions. However, these policies can be costly, with some more expensive than others. The value of reducing such emissions is not $\$ 0$, and it is not infinite. Some imaginable fuel economy standards, for example, would be very stringent, while others would be very lenient. What level of stringency is optimal, if a central goal of those standards is to reduce carbon dioxide emissions? To confront the challenge of climate change effectively, the public is best served by policies that have benefits in excess of costs, and that maximize net benefits.

A key tool in identifying such policies is the social cost of carbon (SCC), which represents the monetized damages associated with a one metric ton increase in $\mathrm{CO}_{2}$ emissions. In principle, the SCC illustrates the dollar value all of the future damages associated with the change in climate due to the release of an additional ton of $\mathrm{CO}_{2}$, including (but not limited to), mortality and other health effects from excess heat and natural disasters, depressed agricultural production, reductions in labor productivity, disruption of energy systems, increased risk of violent conflict, property damage from hurricanes and floods, and mass migration out of affected regions. The SCC therefore reflects how much society should be willing to pay to reduce carbon dioxide emissions by a ton.

With this information, policymakers can easily conduct cost-benefit analysis of regulations that reduce $\mathrm{CO}_{2}$ emissions. The costs to the economy of lowering emissions (e.g., imposing fuel economy standards on car manufacturers) are naturally calculated in dollars. And with the SCC, the benefits of $\mathrm{CO}_{2}$ emissions reductions are converted into dollars. The result is an apples-to-apples comparison of an individual regulation's benefits and costs, both measured in dollars.

From the standpoint of law and practice, this conversion is extraordinarily helpful. In the United States, some legislation formally requires agencies to conduct cost-benefit analysis, and prevailing Executive Orders, supported by both Republican and Democratic presidents, require such an analysis for all major regulations, including those designed to reduce carbon emissions. Though the use of cost-benefit analysis is not 
without controversy, there is a strong argument in favor of conducting such an analysis, and giving serious consideration to it, if the goal is to ensure that regulations best promote the American people's interests. ${ }^{1}$

Following the Supreme Court's decision in U.S. EPA vs. Massachusetts (2007), the U.S. government has been required to issue at least some regulations to reduce greenhouse gas emissions, but it lacked a consistent SCC with which to inform its judgments. In 2009, therefore, the Obama administration issued a temporary SCC and formed an Inter-agency Working Group (IWG) that was tasked with developing a robust SCC, based on the best available science and economics. The work was completed in 2010 and then successively updated, which ultimately produced a value of $\$ 52$ per ton of $\mathrm{CO}_{2}$ in $2020 .^{2}$ The same methods were used to develop a social cost of methane, another potent greenhouse gas, in 2016. ${ }^{3}$ Following a request from the Obama administration, the National Academies of Sciences, Engineering, and Medicine (NAS) released a report on how to bring the SCC closer to the frontier of climate science and economics in January 2017.

Not long after that report's release, the Trump administration disbanded the IWG and reduced the SCC to between $\$ 1$ and $\$ 7$ (see left panel of Figure 1), making changes in assumptions that did not follow the NAS recommendations and that were difficult to justify based on science and economics. ${ }^{4}$ In the past four years, the controversial and substantially lower SCC estimates used by the Trump administration have helped to pave the way for the rollback of environmental regulations. For example, as illustrated in Figure 2, the Trump administration's 2017 reconsideration and substantial weakening of Obama-era fuel economy standards was merited, on cost-benefit grounds, with its lower SCC, but would not have been so justified with the IWG SCC.

\footnotetext{
${ }^{1}$ Livermore and Revesz, Reviving Rationality.

2 Interagency Working Group, "Technical Support Document" (2013).

3 Interagency Working Group, "Technical Support Document" (2016).

${ }^{4}$ Greenstone, Congressional Testimony.
} 


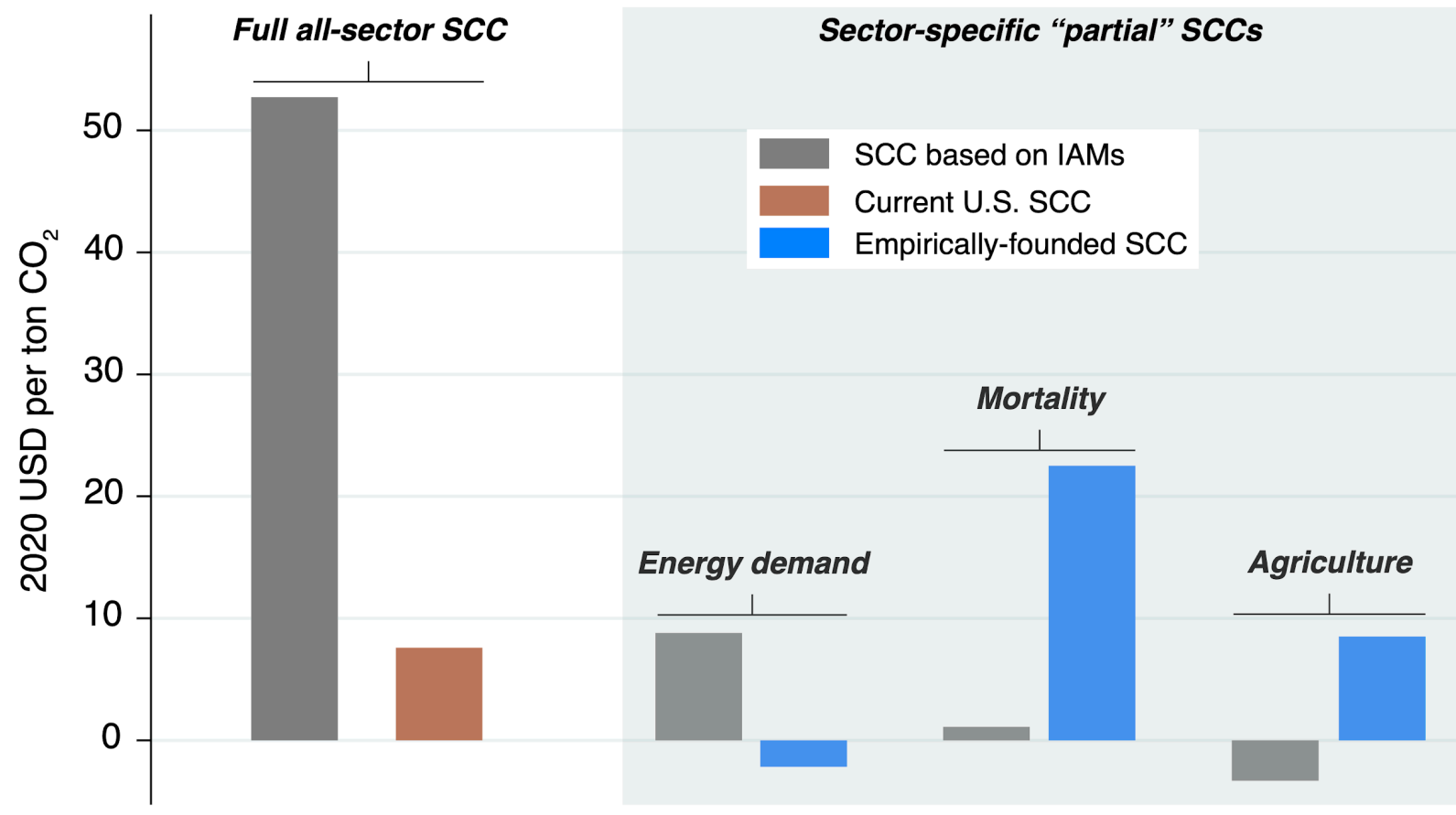

Figure 1: Current U.S. Social Cost of Carbon (SCC) is behind frontier science. This figure compares current and past U.S. federal SCCs to those produced by recent scientific and economic research. The full all-sector SCCs shown on the left are U.S. federal SCCs used under the Obama administration (grey) and the Trump administration (brown). Sector-specific "partial" SCCs on the right come from the Interagency Working Group (IWG) 2013 implementation of the FUND model (grey) and recent scientific literature (blue). Sources: Rode et al. (2020b), Carleton et al. (2020), Moore et al. (2017), and Anthoff and Tol (2014), as decomposed by Diaz (2014). All estimates indicate the willingness-to-pay to avoid an increase in emissions in the year 2020, are shown in 2020 USD, rely on an approximate "business-as-usual" emissions scenario (e.g., RCP 8.5), and use a 3 percent discount rate.

Since its release in 2010, the SCC has played a central role in climate policy both domestically and internationally. For example, as of 2017 the federal government had used the SCC to assess the value of over eighty regulations with a combined $\$ 1$ trillion in estimated gross benefits. ${ }^{5}$ At least eleven state governments have begun using an SCC to guide policy, most notably in Illinois and New York, where governments use the SCC to value "zero-emissions credits" paid to producers of clean energy. ${ }^{6}$ Meanwhile, several other countries, including Canada, France, Germany, Mexico, Norway, and the United

\footnotetext{
${ }^{5}$ Nordhaus, "Revisiting the Social Cost of Carbon."

${ }^{6}$ Institute for Policy Integrity, "The Cost of Carbon Pollution."
} 
Kingdom, have referred to the experience of the United States to implement their own SCC estimates, with some adopting estimates wholesale from the IWG. ${ }^{7}$

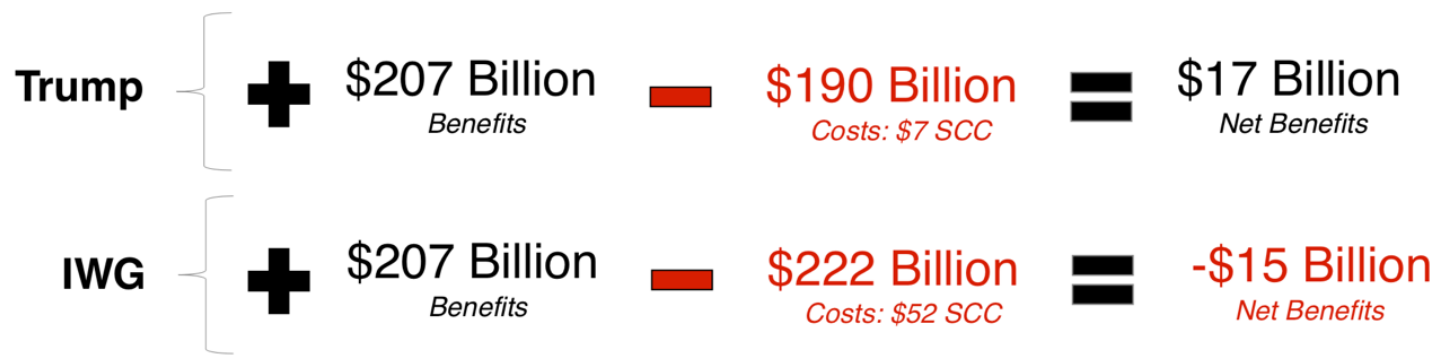

Figure 2: Current U.S. SCC used to justify rollbacks of fuel-economy standards. Figure displays an example regulatory cost-benefit analysis (CBA) using two different SCCs. The values shown are the costs and benefits of a 2017 Environmental Protection Agency (EPA) and National Highway Traffic and Safety Administration (NHTSA) rollback of fuel economy standards for 2021-2026 model-year vehicles. The top row displays the benefits and costs of the rollback using the 2017 Trump administration 3 percent discount rate SCC, taken directly from Table I-I and Table VII-286 of EPA and NHTSA (2017). The bottom row uses the same benefit estimate, but calculates the costs using the 2013 IWG 3 percent discount rate SCC (i.e., the Obama administration SCC), leaving all other assumptions the same across rows (IWG, 2013). Cost estimates incorporate damages from carbon emissions and other factors, such as the monetary cost of fuel. Costs from sources other than carbon emissions account for $\$ 178$ billion of costs in both rows. Both costs and benefits are converted from 2018 to 2020 dollars using the BEA CPI inflation calculator.

In many respects, the SCC is the "straw that stirs the drink" for most domestic climate policies, determining in some cases whether or not regulatory action can proceed. ${ }^{8}$ But the national SCC can also influence the direction of international climate negotiations: experience demonstrates that meaningful U.S. action can leverage large reductions in emissions from other countries that reduce the climate damages that Americans must contend with. ${ }^{9}$

Rapid scientific and economic advances in the last decade mean that there is now an urgent need to update the SCC. The Obama-era SCC relied on the science and data

\footnotetext{
7 U.S. GAO, "Social Cost of Carbon"

8 Sunstein, "Watch for Biden Decision on Unsung Climate Metric."

${ }^{9}$ Houser, "Calculating the Climate Reciprocity Ratio."
} 
available at the time, often making simplifying assumptions that are now understood to be invalid or unnecessary. Recognizing the likely advance of understanding, the IWG explicitly called for "update[s] over time to reflect increasing knowledge of the science and economics of climate impacts."10 Despite some incremental changes, however, a wholesale update was never conducted. The consequence is that neither the Trump nor Obama SCC incorporates the explosion of data and research since 2010 that has dramatically expanded knowledge of the climate, economy, and the relationship between the two. A defining feature of the best new research is that it relies on large-scale data sets, rather than assumptions that are often unverifiable.

A number of these new, empirically grounded studies indicate that the underpinnings of the current SCC are no longer valid in terms of, for example, their projected impacts on mortality rates, energy demand, and agricultural productivity. ${ }^{11}$ The right panel of Figure 1 shows three of the sector-specific component or "partial" SCC estimates developed in recent years (blue), as they compare to the same components of the federal SCC developed in 2013 (grey). New estimates for two of three recently studied SCC sectors (mortality and agriculture) indicate substantially larger damages from $\mathrm{CO}_{2}$, suggesting that the SCC, as settled in 2013, is too low.

Besides advancing understanding about the overall impacts of climate change, these data-driven updates to the SCC have uncovered large differences in the impacts of climate change both within and across countries that were invisible with previous approaches. The key finding is that climate change is projected to disproportionately harm today's poorest populations, exacerbating concerns about environmental justice. ${ }^{12}$ These distributional findings are only visible with the detailed data that characterize the new wave of research. As just one example, even within a wealthy country like the United States, climate change is projected to cause economic damages in the poorest 5 percent of counties that are approximately nine times larger on average by the end of the century than in those in the richest 5 percent. ${ }^{13}$ Put plainly, this new research

\footnotetext{
10 Interagency Working Group, "Technical Support Document" (2010).

11 Carleton et al., "Valuing the Global Mortality"; Rode et al., "Estimating a Social Cost of Carbon"; Diaz \& Moore, "Quantifying the Economic Risks"; Moore et al., "New Science of Climate Change Impacts".

12 See, for instance, Hsiang et al., Estimating Economic Damage from Climate Change in the United States."

13 Id
} 
makes it possible to assess who is most affected by climate policies - insight that is out of reach under the current SCC framework.

Revising the U.S. SCC based on a new and more durable foundation would return the SCC to the frontier of understanding about the risks from climate change and lead to better policy that protects Americans against unnecessary climate risks. Moreover, such an update would undoubtedly influence policy abroad, which directly affects the wellbeing of Americans, since the climate is equally affected by emissions from Chicago, as those from Beijing, Mumbai, Paris, and Riyadh.

This paper outlines a two-step approach to updating the U.S. SCC that returns it to the frontier of knowledge. The Biden administration can initiate the first step immediately and simply involves implementing the IWG's approach again with a discount rate of no higher than 2 percent, which reflects profound changes in international capital markets that make the current values difficult to justify. At a discount rate of $2 \%$ the SCC in 2020 is $\$ 125 .^{14}$

The second step is for the Biden administration to launch a reconstituted IWG and task it with a comprehensive updating of the SCC. There are seven key "ingredients" that should go into such a process and the next section identifies each of them, explains what was done in the past, describes how understanding has advanced since 2009-2010, and makes a specific recommendation. The paper's final section details multiple pathways towards combining these ingredients to produce an updated SCC. Importantly, none of these pathways can be implemented immediately; a reconstituted IWG's work could take several months.

\section{The Seven Key Ingredients for a Revised SCC}

Calculating the SCC requires a model that accounts for the future growth of the economy, the relationship between emissions and climate change, the effect of climate change on the economy, and a number of other factors. Such models are referred to as Integrated Assessment Models (IAMs), since they combine scientific and economic

\footnotetext{
${ }^{14}$ New York State Department of Environmental Conservation, "Establishing a Value of Carbon"; New York State Energy Research and Development and Resources for the Future, "Estimating the Value of Carbon: Two Approaches."
} 
models to evaluate the impacts of carbon emissions. The Obama-era IWG estimated the SCC using three existing IAMs - DICE, FUND, and PAGE - which were developed in the 1990 s and have been widely used in the economic and scientific literature. ${ }^{15}$

There are seven "ingredients" necessary to construct the SCC. The first four are often referred to as "modules" (see Figure 3):

1. A socioeconomic and emissions trajectory, which predicts how the global economy and $\mathrm{CO}_{2}$ emissions will grow in the future;

2. A climate module, which measures the effect of emissions on the climate;

3. A damages module, which translates changes in climate to economic damages; and

4. A discounting module, which calculates the present value of future damages.

In addition, there are three cross-cutting modeling decisions that affect the entire process:

1. Whether to include global or instead only domestic climate damages;

2. How to value uncertainty; and

3. How to treat equity.

${ }^{15}$ Nordhaus, "Economic Aspects of Global Warming"; Anthoff and Tol, "The Income Elasticity of the Impact of Climate Change"; Hope, "The PAGE09 Integrated Assessment Model." 


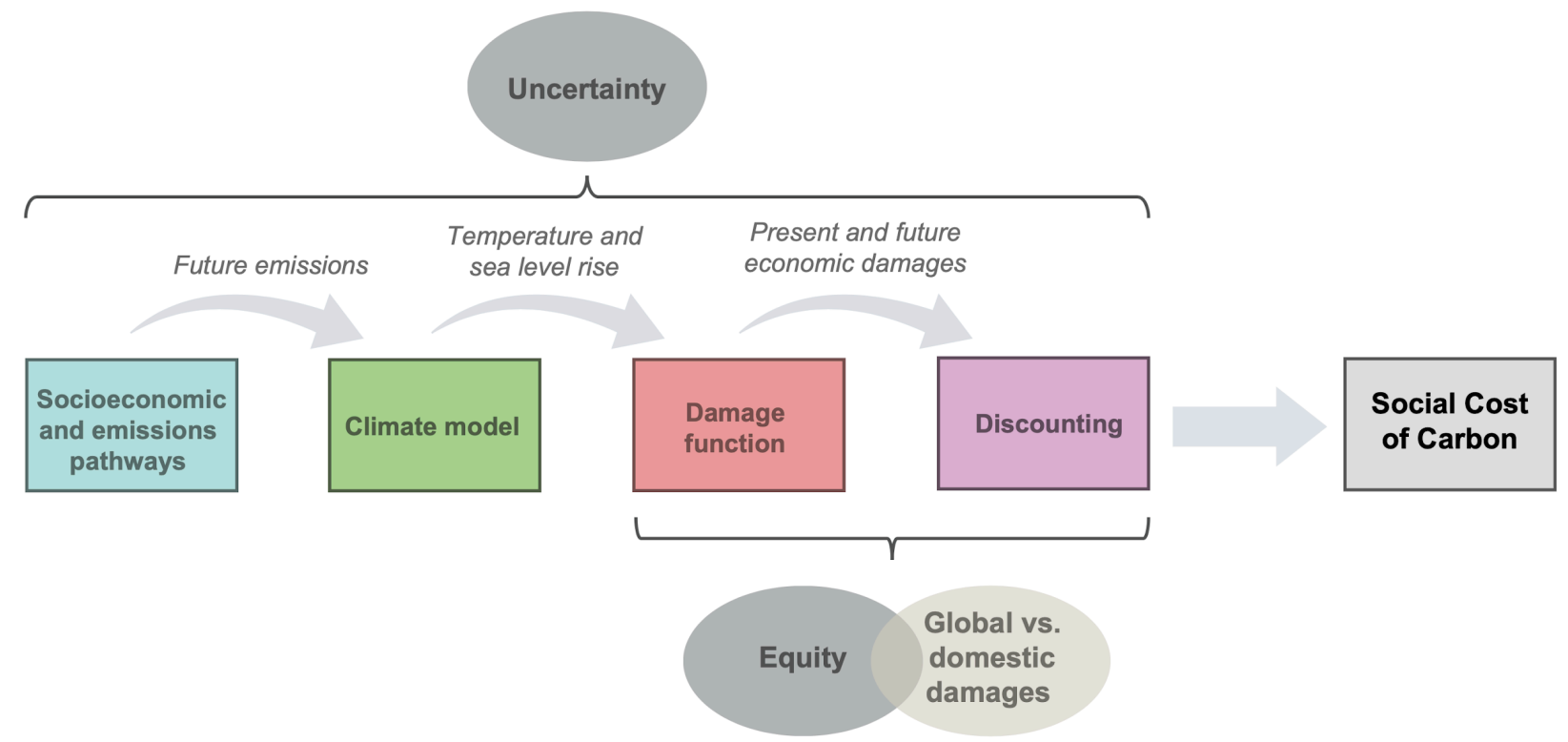

Figure 3: Seven ingredients for calculating the Social Cost of Carbon. This figure displays the four "modules" that compose the SCC (colored boxes), and the three key modeling decisions (grey ovals) that together form the seven "ingredients" necessary to compute an SCC.

Updating the SCC so that it is built on a foundation of frontier science and economics would require a newly constituted IWG to make decisions regarding each of these seven ingredients. However, the IWG need not start from scratch; some required updates are already clear. Due to significant advances in climate modeling and in climate impact analysis, as well as profound changes in global capital markets, it is essential to update the climate and damage modules and to change the rate of discounting. It is additionally essential to update the Trump administration's U.S. SCC to reflect global, as opposed to domestic only, damages, based on an overwhelming consensus amongst scientific and economic experts. Failing to account for these advances would leave any new SCC open to well-founded scientific criticism. It could also leave a new SCC vulnerable to legal invalidation; courts review agency decisions to ensure that they are not "arbitrary or capricious," and if a new SCC were not based on scientific advances it could be challenged on exactly that ground. There are also valuable opportunities to update the other three ingredients, but to varying degrees the scientific and/or policy case for doing so is less urgent.

This paper can be thought of as a "recipe," outlining ways to bring the U.S. government's SCC back up to the scientific frontier. This section briefly explains each of 
the seven key ingredients, describes how they were handled by the IWG in 2010, and makes recommendations to update each.

\section{A. Essential Updates to the SCC}

\section{Ingredient 1: Climate Module}

Background: The development of an SCC requires a climate model that converts carbon emissions into changes in the global climate. Specifically, these models must characterize the relationship between emissions and atmospheric $\mathrm{CO}_{2}$ concentrations and the relationship between atmospheric $\mathrm{CO}_{2}$ and changes in the climate, including both warming and sea level rise. All three IAMs used by the IWG included highly simplified climate models. A core input into each of these models was the Equilibrium Climate Sensitivity (ECS), which determines the total global warming realized from a doubling of atmospheric carbon concentrations. The ECS has a substantial impact on the SCC but its true value is not known with scientific certainty.

2010 IWG Approach: The IWG relied on the climate models within each IAM. However, to ensure that the ECS values used reflected the best available science at the time, the IWG harmonized the ECS across all models by using a probability distribution that reflected the likelihood of different possible climate outcomes at the end of the century according to the Intergovernmental Panel on Climate Change's (IPCC) Fourth Assessment Report. This was the only component of each IAM's climate model that the IWG calibrated to match scientific evidence.

Progress: Recent evidence makes clear that the IAMs used to calculate the IWG SCC, even with a harmonized ECS, are outdated, as they do not reflect a substantial body of new research quantifying multiple links in the causal chain from emissions to temperature change. ${ }^{16}$ In particular, DICE, FUND, and PAGE substantially underestimate the speed of temperature increase, relative to climate models that satisfy the NAS criteria for meeting scientific standards (Figure 4). ${ }^{17}$ For example, higher atmospheric $\mathrm{CO}_{2}$ concentrations cause the oceans to warm and acidify, which makes

\footnotetext{
${ }^{16}$ Dietz et al., "Are Economists Getting Climate Dynamics Right"; Mattauch et al., "Steering the Climate System"; NAS, "Valuing Climate Damages."

${ }^{17}$ NAS, "Valuing Climate Damages," Recommendation 4-1
} 
them less effective at removing $\mathrm{CO}_{2}$ from the atmosphere. The consequence is a positive feedback loop that accelerates warming. ${ }^{18}$ However, this dynamic is missing from both the DICE and PAGE climate modules.

The fact that existing IAMs do not reflect the well-developed climate science literature substantially influences the magnitude of the SCC. ${ }^{19}$ Importantly, the delayed projection of warming in the IAMs' climate models means that resulting estimates of the SCC are likely to be too low. The delay pushes warming further into the future, which is discounted more heavily, as shown in the bottom panel of Figure 4.

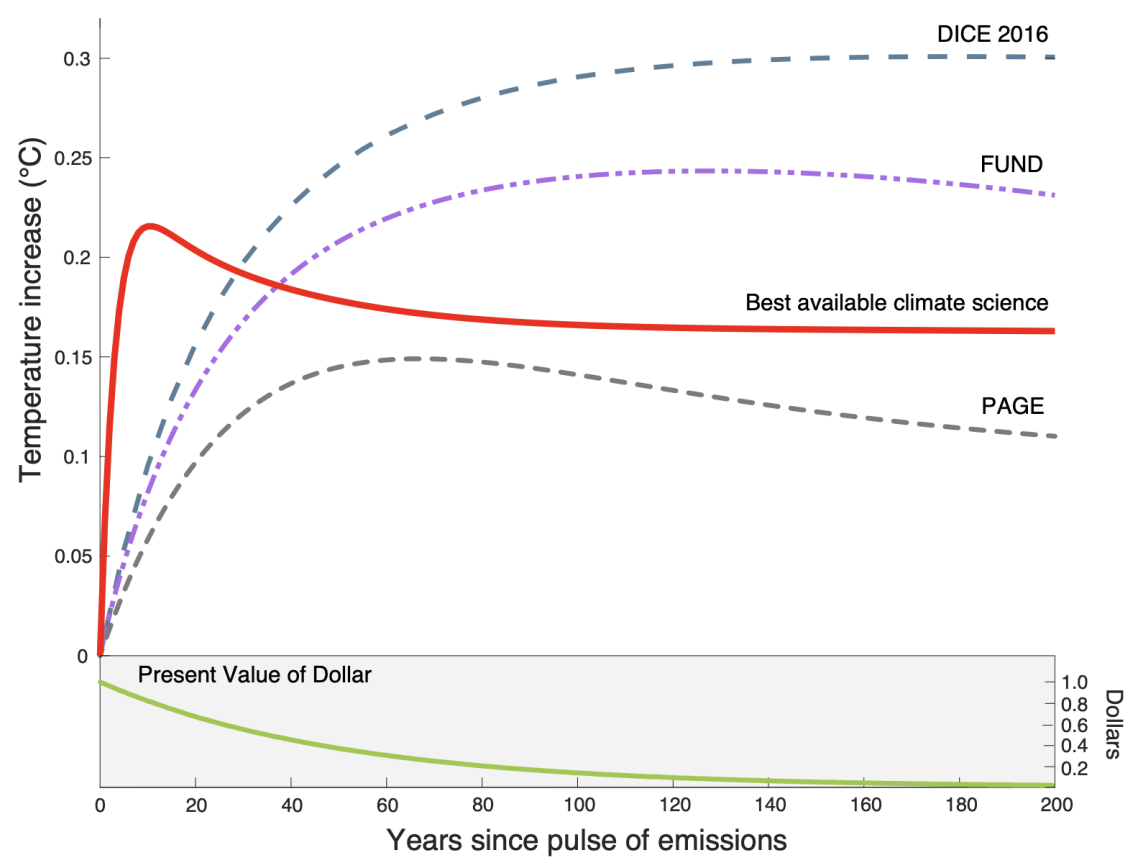

Figure 4: Current Integrated Assessment Models do not reflect well-developed climate science. Dynamic temperature response to a $100 \mathrm{GtC}$ impulse of $\mathrm{CO}_{2}$ from the CMIP 5 climate model ensemble (red solid line, labeled "best available climate science") versus the three IAMs used to compute the U.S. government's SCC (DICE, FUND, and PAGE). The lower panel shows the present discounted value of $\$ 1$, discounted using a 2 percent discount rate. Source for top panel: Dietz et al., 2020.

Recommendation: It is vital that an updated SCC relies on a climate model that accurately reflects the climate system's functioning. Because any SCC calculation requires fully capturing the uncertainty surrounding the impact of $\mathrm{CO}_{2}$ on temperature

\footnotetext{
18 Dietz et al., "Are Economists Getting Climate Dynamics Right."

${ }^{19} \mathrm{Id}$
} 
and other climate variables, however, it would be computationally infeasible to replace IAM climate models with state-of-the-art Earth system models that capture the physics, chemistry, and biology of the atmosphere, oceans and land at high spatial resolution. Therefore, a simple Earth system model that can conduct uncertainty analysis while also matching predictions from these more complex models is necessary.

The first part of our ${ }^{20}$ climate model recommendation is that IWG use the simple Earth system model FAIR to project changes in temperature. ${ }^{21}$ The FAIR model satisfies all criteria set by the NAS for use in an SCC calculation. ${ }^{22}$ Importantly, this model generates projections of future warming that are consistent with comprehensive, stateof-the-art models and it can be used to accurately characterize current best understanding of the uncertainty regarding the impact that an additional ton of $\mathrm{CO}_{2}$ has on global mean surface temperature (GMST). Finally, FAIR is easily implemented and transparently documented, ${ }^{23}$ and is already being used in updates of the SCC. ${ }^{24}$

A key limitation of FAIR and other simple climate models is that they do not represent the change in global mean sea level rise (GMSL) due to a marginal change in emissions. However, statistical methods can be used in combination with long historical records of both temperature and sea level to build a semi-empirical model of the relationship between GMSL and GMST. ${ }^{25}$ Such models are readily available ${ }^{26}$ and can enable the inclusion of marginal damages due both to warming and to projected changes in sea level. An important potential caveat is that available semi-empirical models of GMSL, in addition to more complex bottom-up models, may underestimate future sea level rise due to their inability to capture plausible future dynamics that are not observed in the historical record (e.g., ice cliff collapse).

\footnotetext{
20 Throughout, "we" or "our" refers solely to the views of Carleton and Greenstone and not necessarily those of EPIC, the University of Chicago, or the University of California, Santa Barbara.

${ }^{21}$ Millar et al., "A Modified Impulse-Response Representation."

22 NAS, "Valuing Climate Damages."

${ }^{23}$ FAIR's source code can be accessed here: https://github.com/OMS- NetZero/FAIR/.

${ }^{24}$ Dietz et al. "Are Economists Getting Climate Dynamics Right"; Carleton et al., "Valuing the Global Mortality Consequences"; Rode et al., "Labor Supply in a Warmer World"; Rode et al., "Estimating a Social Cost of Carbon for Global Energy Consumption."

${ }^{25}$ NAS, "Valuing Climate Damages."

${ }^{26}$ See, for example, Kopp et al., "Temperature-Driven Global Sea-Level Variability."
} 
The second part of our climate model recommendation is that the IWG use semiempirical models to project changes in sea level based on changes in global mean surface temperature from FAIR.

Finally, a strength of simple climate models like FAIR is that they can project GMST, accounting for climatological uncertainty, both with and without a marginal increase in emissions, which is necessary to compute the social cost of one additional ton of $\mathrm{CO}_{2}$. However, they are not able to provide local climate projections at, for example, the county level. This introduces a challenge, as socioeconomic trajectories are available nationally and, as discussed below, recovering a valid damage function requires that climate impacts be estimated locally. It is possible, however, to use high spatial detail in socioeconomic and climatic conditions to estimate damages that are then calibrated to GMST (and GMSL, for sectors where sea level rise is an important driver of climate change impacts) in a second stage. ${ }^{27}$

Therefore, the third part of our climate model recommendation is that the damage function itself should relate total socioeconomic damages to changes in global mean surface temperature (and global mean sea level rise where appropriate).

\section{Ingredient 2: Damages Module}

Background: A "damage function" translates changes in the physical climate (e.g., temperature and sea level rise) into monetized impacts on the economy. In some IAMs, a single damage function is calibrated to represent all categories of climate impact (e.g., PAGE), while in others, separate damage functions are modeled for individual impact categories (e.g., FUND). In DICE, a single damage function is used, but it is calibrated based on individual sector-specific damage estimates. ${ }^{28}$

At least two problems have plagued the IAM damage functions. First, they are primarily derived from ad-hoc assumptions and simplified relationships, not large-scale empirical evidence. Further, the IAM damage functions have tended to treat the world as nearly homogeneous, dividing the globe into at most sixteen regions. This aggregation

\footnotetext{
${ }^{27}$ NAS, "Valuing Climate Damages"; Carleton et al., "Valuing the Global Mortality Consequences;" Rode et al., "Labor Supply in a Warmer World;" Rode et al., "Estimating a Social Cost of Carbon for Global Energy Consumption."

${ }^{28}$ Nordhaus, "The 'DICE' Model."
} 
misses a great deal, especially because there are important nonlinearities in the relationship between temperature and human well-being that are obscured by substantial aggregation. For example, a given increase in temperature will have very different impacts in Arizona than it will in northern Minnesota. For both of these reasons, these damage functions have been heavily criticized in recent years. ${ }^{29}$

2010 IWG Approach: When the IWG developed the first SCC in 2010, existing IAM damage functions were essentially the only feasible option. As a result, there were few if any alternatives and the IWG kept the damage functions originally included in DICE, FUND, and PAGE.

Progress: In the last dozen years, there have been great advances in computing power, access to data from around the world, and econometric methods designed to quantify climate change impacts. A result has been an explosion of empirical research that has greatly deepened science's understanding of the economic impacts of climate change. ${ }^{30}$ Relative to 2009, there is almost an embarrassment of riches, with, for example, at least 110 empirical studies on climate change's economic impacts published between 2010 and 2016 alone. $^{31}$

So how should one choose among all of these studies when developing an updated damage function? To make full use of scientific advances, any modern damage function must now meet three criteria:

1. Empirically derived and plausibly causal: Damage functions should be derived from empirical estimates that reflect plausibly causal impacts of weather events on socioeconomic outcomes.

Because the climate has remained stable throughout modern human history, it is difficult to isolate experimental variations in the long-run climate. However, a large and growing empirical literature leverages modern econometric methods to uncover causal impacts of short-run weather events on a host of socioeconomic

\footnotetext{
29 Pindyck, "Climate Change Policy: What Do the Models Tell Us?"

${ }^{30}$ Carleton and Hsiang, "Social and Economic Impacts of Climate;" Dell et al., "What Do We Learn from the Weather?"; Deschenes and Greenstone, "The Economic Impacts of Climate Change."

31 Carleton and Hsiang, "Social and Economic Impacts of Climate."
} 
outcomes, from agricultural output to mortality rates to energy use. ${ }^{32}$ When combined with empirical estimates of differences in populations' responses to weather events (discussed in criterion three below), this literature provides a strong foundation for understanding the socioeconomic effects of weather, and its approach should be reflected in a new IWG's damage function.

The damage functions from FUND, DICE, and PAGE used by the IWG do not meet this criterion. They are only loosely calibrated to empirical evidence and/or rely on outdated estimates that fail to isolate the role of changes in the climate from economic variables such as income and institutions. For example, the majority of the studies used in FUND's sector-specific damage functions were published prior to 2000, and all likely suffer from the influence of unobserved factors that are correlated with temperature. Similarly, early versions of DICE utilized a damage function that was only loosely tied to empirical literature (Diaz and Moore, 2017; Nordhaus, 2010), while the recent DICE update continues to rely on empirical papers that fail to identify plausibly causal effects (Nordhaus and Moffat, 2017).

\section{Capture local-level nonlinearities for the entire global population: Damage} functions should be estimated with data that represent the entire global population (not just high-income, temperate regions). Further, damage functions should account for "nonlinear" effects of climate variables at a local level.

Dramatic reductions in computing costs and increased data availability have enabled researchers to identify the effects of climate change on social and economic conditions at local scale across the globe. This body of work has uncovered that many socioeconomic outcomes display a strongly nonlinear relationship with climate variables - that is, the effects of climate change are not identical everywhere, but are instead sensitive to prior socioeconomic and climatic conditions. ${ }^{33}$ For example, both extreme cold and extreme heat increase mortality rates, while moderate temperatures have little impact. ${ }^{34}$ In addition,

\footnotetext{
32 Carleton and Hsiang, "Social and Economic Impacts of Climate;" Dell et al., "What Do We Learn from the Weather?"

${ }^{33}$ Carleton and Hsiang, "Social and Economic Impacts of Climate."

${ }^{34}$ Gasparinni et al., "Mortality Risk Attributable to High and Low Ambient Temperature;" Deschênes and Greenstone, "Climate Change Mortality, and Adaptation."
} 
this research has documented large differences in climate impact relationships between rich and poor, ${ }^{35}$ hot and cold ${ }^{36}$ and agricultural and non-agricultural ${ }^{37}$ regions. The significant differences in the results across different places imply that the additional damage caused by a given increment of warming may lead to substantially different outcomes around the globe, depending on the characteristics of the local economy, demographics, and region.

The existing IAMs' damage functions fail to adequately characterize nonlinearities, to disaggregate local impacts around the world, or to include information from lower-income, hotter regions of the globe. For example, the PAGE model damage function is calibrated based on an empirical analysis that only includes data from the United States. ${ }^{38}$ Similarly, the FUND mortalityspecific damage function is calibrated by an analysis ${ }^{39}$ that draws on multiple studies, but only one of these studies ${ }^{40}$ leverages actual mortality data, and only from Los Angeles, New York, Tokyo, Israel, the Netherlands, Taiwan, and the United Kingdom. None of these locations have the combination of a hot climate and low incomes that characterize the regions where several billion people currently live. Moreover, these models divide the globe into at most sixteen distinct regions, missing important spatial detail.

A failure to capture globally representative, locally varying, nonlinear relationships is a grave threat to the validity of damage functions. This is illustrated in Figure 5, where distinct mortality-temperature responses are shown for Oslo, Norway and Accra, Ghana, as well as for the global average. In Oslo, climate change is likely to save lives, as the mortality rate is highly sensitive to cold and temperatures become more moderate under climate change. In contrast, low incomes in Accra lead to extremely high mortality-sensitivity to heat, and large increases in heat-related mortality under climate change. It is also apparent that the global average mortality-temperature response function is a very poor representation of the impact of climate change in both Oslo and Accra. Ignoring

\footnotetext{
35 Davis and Gertler, "Contribution of Air Conditioning Adoption."

${ }^{36}$ Heutel et. al., "Adaptation and the Mortality Effects of Temperature."

${ }^{37}$ Cai et al., "Climate Variability and International Migration."

38 Cline, "The Economics of Global Warming."

39 Tol, "Estimates of the Damage Costs of Climate Change."

${ }^{40}$ Martens, "Climate Change, Thermal Stress, and Mortality Changes."
} 
such differences by applying the global response function to Oslo and Accra, instead of the local responses, would dramatically misrepresent the impacts of climate change around the world.
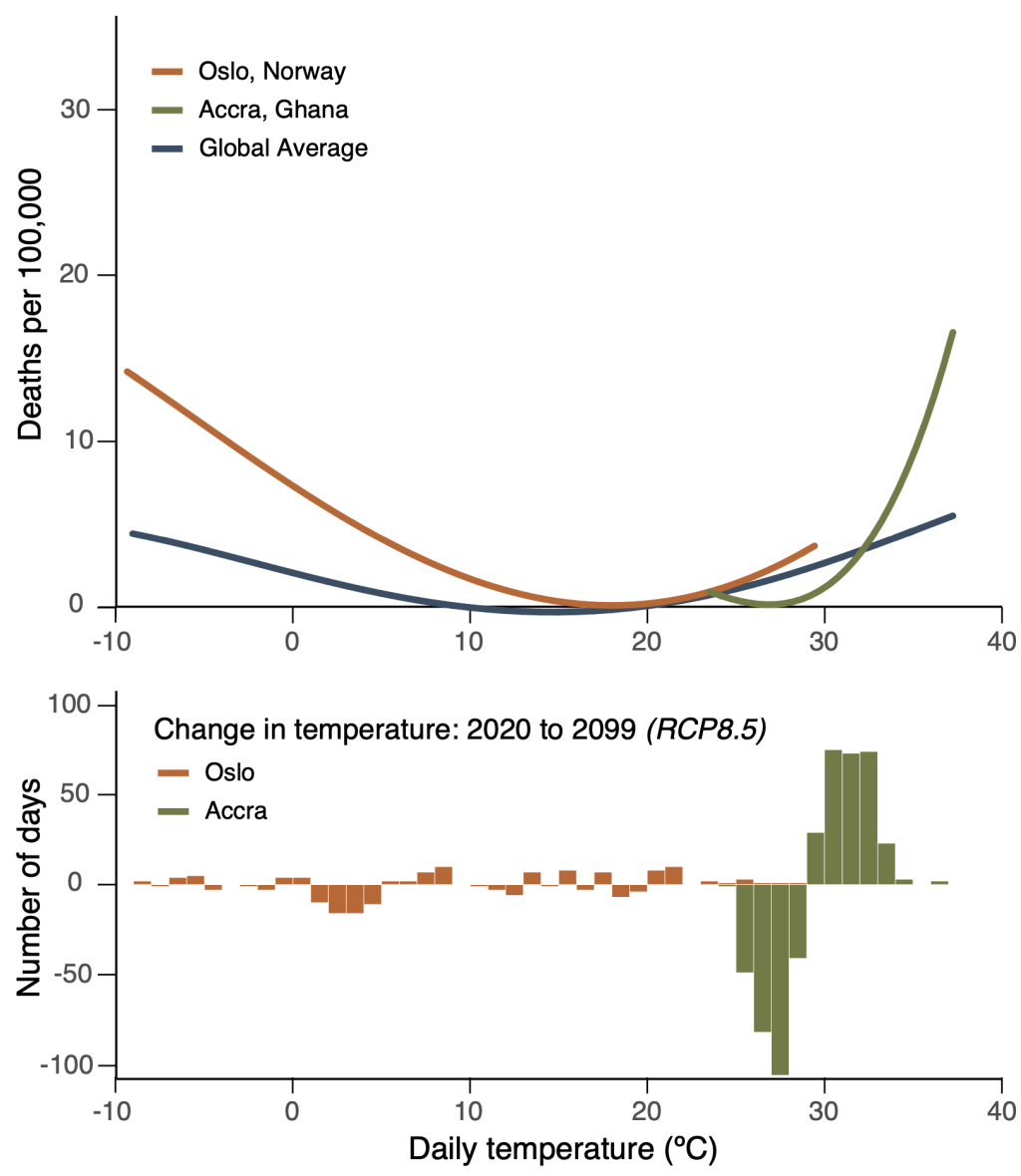

Figure 5: Climate change will have disparate impacts on different geographic regions. Figure displays estimated relationships between mortality rates for ages $>65$ years and temperature (top panel), along with anticipated changes in the temperature distribution from climate change (bottom panel), for Oslo, Norway (orange) and Accra, Ghana (green). The top panel also shows a multi-country average mortalitytemperature relationship (blue). In the bottom panel, the difference between the 2099 and 2020 temperature distributions is shown for Oslo and Accra, using a high-emissions scenario (RCP8.5) from the CCSM4 climate model. Top panel mortality-temperature relationships for Oslo and Accra are only shown for the range of temperatures projected to be experienced in each location between 2020 and 2099. The global average response includes data from 38 percent of the global population. Source: Carleton et. al., 2020 .

While further advances in data collection and computing power are needed to derive damage functions for all sectors in all countries at high spatial resolution, 
substantial improvements over the existing IAMs are feasible. Further, recent research has developed methods for estimating worldwide climate impacts by inferring damages in data-poor regions based on data-rich regions that have similar characteristics. ${ }^{41}$

3. Inclusive of adaptation: Damage functions should reflect that people, firms, and governments make defensive investments that provide protection against climaterelated risks, and that these investments are costly.

As climate change unfolds, individuals, governments, and firms will make innumerable decisions and investments to respond to the gradually changing environment. Damage functions within DICE, FUND, and PAGE involve very different assumptions about such compensatory investments and their costs, the majority of which are not based on real-life observations of adaptation. ${ }^{42}$

The damage function should include both the estimated benefits and costs of future adaptive investments. While earlier empirical studies failed to account for the benefits of adaptation, ${ }^{43}$ a growing literature covering multiple sectors is developing damage estimates that reflect the benefits of adaptation. ${ }^{44}$

However, these compensatory investments are not free - any updated damage function should also account for costs of adaptation. ${ }^{45}$ Some progress has been made to infer these costs from available data, ${ }^{46}$ but this is an active area of research. Damage functions should capture adaptation costs wherever possible.

Estimated damage functions that meet the above criteria lead to dramatically different understandings about the economic impacts of climate change, compared to the older

${ }^{41}$ Carleton et al., "Valuing the Global Mortality Consequences."

${ }^{42}$ Diaz and Moore, "Quantifying the Economic Risks of Climate Change."

${ }^{43}$ See, for example, Deschênes and Greenstone, "The Economic Impacts of Climate Change."

${ }^{44}$ See, for example, Auffhammer, "Climate Adaptive Response Estimation;" Deryugina and Hsiang, "The Marginal Product of Climate;" Heutel et al., "Adaptation and the Mortality Effects of Temperature."

${ }^{45}$ Estimates of adaptation costs are essential when computing the total damages of climate change. In contrast, under a strict set of assumptions, the marginal benefits and marginal costs of additional adaptation cancel each other out in the calculation of the damages from a marginal ton of $\mathrm{CO}_{2}$ emissions, making adaptation cost estimates unnecessary for the SCC when these assumptions are taken.

${ }^{46}$ Carleton et al., "Valuing the Global Mortality Consequences." 
damage functions. For example, one recent study found a mortality-only SCC estimate that is more than ten times larger than the total health impacts within the FUND IAM. ${ }^{47}$ Further, its estimate of the loss from higher mortality rates in 2100 accounts for 49-135 percent of total damages across all sectors from the three leading IAMs. Another recent study derived an agricultural damage function that meets some aspects of the criteria above and found a substantial, positive, agriculture-only SCC, while FUND's agricultural SCC is negative (see Figure 1). ${ }^{48}$ In other words, by using more comprehensive techniques, this study overturned past findings that suggested that climate change would benefit agriculture, instead finding that it would cause substantial damage.

It is noteworthy that meeting these criteria does not always increase estimated damages. For example, one study quantifying the impacts of climate change on global energy expenditures found a small, energy-only SCC estimate of -\$2. This finding was attributable largely to net savings from reductions in heating and differences in the responsiveness of electricity demand to high temperatures in high- versus low-income regions of the world. ${ }^{49}$ This estimate stands in stark contrast to the FUND model, where the energy-only SCC is $\$ 8$ ( $\$ 6$ of which is attributable to Chinese cooling demand only) and constitutes 90 percent of the total, all-sector SCC. ${ }^{50}$

These examples demonstrate that research that meets the three criteria described here will fundamentally alter prior estimates of the economic impacts of climate change.

\section{BEGIN BOX}

\section{Box title: Top-down GDP-based estimates of climate damages}

Another approach to updating damage functions guided by the three listed criteria is "top-down" in nature, relying on statistical relationships between GDP and climate variables (generally, temperature) to quantify the impacts of climate change on aggregate growth in (or levels of) income. ${ }^{51}$ The idea is to use GDP as a wide-reaching measure of economic well-being such that individual socioeconomic sectors do not need

\footnotetext{
47 Id

48 Moore et al., "New Science of Climate Change Impacts."

49 Rode et al., "Estimating a Social Cost of Carbon for Global Energy Consumption."

50 Diaz, "Evaluating the Key Drivers."

51 See, for example, Burke et al., "Global Non-Linear Effect of Temperature;" Dell, et al., "Temperature Shocks and Economic Growth."
} 
to be separately analyzed nor do their interactions need to be explicitly modeled. These top-down empirical results have recently been used to compute updated SCCs. For example, one recent study generated SCCs of about $\$ 400$, nearly an order of magnitude larger than the Obama SCC. ${ }^{52}$

This is an important and rapidly evolving line of research. However, several critiques cause us to conclude that top-down empirical analysis is not currently ready for use in determining the SCC. First, GDP is an incomplete measure of economic well-being and of willingness-to-pay for reducing greenhouse gas emissions. For example, it misses nonmarket outcomes such as mortality and morbidity that are large in magnitude, ${ }^{53}$ and current top-down analyses omit the damages associated with flooding and sea level rise. However, a bottom-up approach that sums sector-specific damages will also be incomplete, as discussed in this paper's last section.

Second, there is a long history of skepticism about the ability of cross-country GDP regressions to provide reliable information on the determinants of growth. ${ }^{54}$ Many of these concerns boil down to questions of misspecification. Regression models can be designed to identify causal relationships between various phenomena - in this case, between GDP growth and its potential causes. With limited available data, however, it is difficult to specify a regression model that can accurately recover the dynamic and potentially slow-moving influence of individual determinants of growth. Moreover, in GDP regressions, each country-year observation is treated as independent from the others, when in fact the growth process is strongly interlinked across countries. ${ }^{55}$ Modeling these interdependencies across space and time is exceptionally difficult with available data.

Third, it is unclear whether a change in temperature affects the level or growth rate of GDP. A test for growth effects of temperature shocks requires estimating a distributed lag model with many lags, but these models (which measure the effects of temperature on growth over time) are difficult to estimate with available data, leaving a good deal of uncertainty in the results. For example, one model was empirically unable to distinguish

\footnotetext{
${ }^{52}$ Ricke et al., "Country-Level Social Cost of Carbon," using statistical estimates from Burke et al., "Global Non-Linear Effect of Temperature," and Dell et al., "Temperature Shocks and Economic Growth."

${ }^{53}$ Hsiang et al., "Estimating Economic Damage from Climate Change in the United States."

${ }^{54}$ Note that this skepticism in the macroeconomics literature has applied both to purely cross-sectional analyses (comparing countries' growth experiences to one another) and to growth regressions exploiting panel data (comparing GDP over time within a country). See Durlauf (2009) for a detailed discussion. ${ }^{55}$ Klenow and Rodriguez-Clare, "Externalities and Growth."
} 
between growth and level effects, ${ }^{56}$ while another rejected evidence of growth effects ${ }^{57}$ and a third found evidence in support of growth effects (at the subnational level) ${ }^{58}$. The answer to this question has first order consequences on climate change projections, so this lack of clarity is not trivial.

Fourth, a paper in this literature notes that the estimated effects of temperature shocks on GDP growth rates appear implausibly large: "If an extra $1^{\circ} \mathrm{C}$ reduces growth by 1.1 percentage points, then it would take only eight years of sustained temperature differences to explain the overall cross-sectional relationship between temperature and income observed in the world today."59 The magnitude of these effects along with concerns about whether there are plausible mechanisms through which temperature can affect economic growth (as opposed to the level of economic activity) together have led to some additional skepticism.

A top-down approach to damage function estimation has strong potential to inform the SCC, particularly because it is challenging to empirically ground the overlap, spillovers, and interactions among individual sectors of damages used in a bottom-up approach. ${ }^{60}$ Therefore, resolving the uncertainties in this expanding literature is an urgent line of inquiry. In the meantime, we believe that a bottom-up approach like that outlined in this paper is a more promising avenue for determining an SCC grounded in real-world data.

\section{END BOX}

Recommendation: We recommend that the Biden administration replace all existing IAM damage functions with those that meet these three criteria.

\section{Ingredient 3: Discount Module}

Background: Along with a set of socioeconomic and emissions scenarios, discussed below, the climate and damages modules together translate a single additional ton of $\mathrm{CO}_{2}$

\footnotetext{
${ }^{56}$ Burke et al. (2015) estimate a five-year distributed lag model that cannot reject zero growth effects (cumulative effect of -0.010 per ${ }^{\circ} \mathrm{C}$ with a $95 \%$ confidence interval of $[-.027,0.008]$ ). The authors conclude: "...we cannot reject the hypothesis that this effect is a true growth effect[s] nor can we reject the hypothesis that it is a temporary level effect."

${ }^{57}$ Kalkuhl and Wenz, "The Impact of Climate Conditions on Economic Production."

${ }_{58}$ Burke and Tanutama, "Climatic Constraints on Aggregate Economic Output."

${ }^{59}$ Dell, Jones and Olken, "Temperature and Income."

${ }^{60}$ NAS, "Valuing Climate Damages"; Kopp and Mignone, "The U.S. Government's Social Cost Of Carbon Estimates."
} 
emissions into a trajectory of additional warming, and a stream of future damages. The final step in the SCC calculation is to express this stream of damages as a single present value, so that future costs and benefits can be directly compared to costs and benefits of actions taken today. Discounting is the process by which each year's future values are reduced to enable comparison with current costs or benefits to society. The "discount rate" determines the magnitude of this reduction. Because $\mathrm{CO}_{2}$ emissions persist in the atmosphere and lead to long-lasting climatological shifts, small differences in the choice of discount rate can compound over time and lead to meaningful differences in the SCC.

There are two reasons for "discounting the future," or more precisely for discounting future monetary amounts, whether benefits or costs. The first is that an additional dollar is worth more to a poor person than a wealthy one, which is referred to in technical terms as the declining marginal value of consumption. The relevance for the SCC is that damages from climate change that occur in the future will matter less to society than those that occur today, because societies will be wealthier. The second, which is debated more vigorously, is the pure rate of time preference: people value the future less than the present, regardless of income levels. While individuals may undervalue the future because of the possibility that they will no longer be alive, it is unclear how to apply such logic to society as a whole facing centuries of climate change. Perhaps the most compelling explanation for a nonzero pure rate of time preference is the possibility of a disaster (e.g., asteroids or nuclear war) that wipes out the population at some point in the future, thus removing the value of any events that happen afterwards.

The government regularly has to make judgments about the discount rate when trading off the costs and benefits of a regulation or project that will endure for multiple years. In general, U.S. government agencies have relied on the Office of Management and Budget's (OMB's) guidance to federal agencies on the development of regulatory analysis in Circular A-4, and used 3 percent and 7 percent discount rates in cost-benefit analysis. ${ }^{61}$ These two values are justified based on observed market rates of return, which can be used to infer the discount rate for the SCC since any expenditures incurred today to mitigate $\mathrm{CO}_{2}$ emissions must be financed just like any other investment. The 3 percent discount rate is a proxy for the real, after-tax riskless interest rate associated with U.S. government bonds and the 7 percent rate is intended to reflect

${ }^{61}$ OMB, "Circular A-4." 
real equity returns like those in the stock market. However, climate change involves intergenerational tradeoffs, raising difficult scientific, philosophical and legal questions regarding equity across long periods of time. There is no scientific consensus about the correct approach to discounting for the SCC. ${ }^{62}$

2010 IWG Approach and Progress: There are two possible approaches to discounting in SCC calculations. First, a fixed discount rate can be used, as was implemented in the IWG SCC calculations. The 2010 IWG used discount rates of 2.5 percent, 3 percent, and 5 percent, while the Trump administration applied 3 percent and 7 percent, in accordance with OMB Circular A-4. The 2010 IWG set the 3 percent discount rate as the central case to be consistent with guidance from the OMB (2003) regarding the interest rate on U.S. government bonds. This decision was also motivated by the assumption that climate damages were projected to be uncorrelated with overall market returns (eliminating the 7 percent rate, derived from equity markets) and thus used insights from asset pricing theory that the riskless interest rate was appropriate. ${ }^{63}$

There have been profound changes in global capital markets since the publication of Circular A-4 in 2003 that make it extraordinarily challenging to justify 3 percent as an accurate estimate of the return on riskless investments. For example, the average tenyear Treasury Inflation-Indexed Security (TIPS) rate over the available record of the index (2003-present) is just 1.01 percent (see Figure 6). ${ }^{64}$ Similarly, recent research has shown that the equilibrium real interest rate has declined substantially since the 1990s, suggesting a lower discount rate is justified. ${ }^{65}$ Additionally, evidence from long-term real estate investments suggests that for climate mitigation, which has payoffs over very long periods of time, discount rates should be even lower than those used to discount costs and benefits of shorter-lived investments. ${ }^{66}$ Overall, our judgement is that it is difficult to defend a 3 percent discount rate for climate investments and there is now a compelling case for a riskless discount rate of no higher than 2 percent. ${ }^{67}$

\footnotetext{
62 Gollier and Hammitt, "The Long-Run Discount Rate Controversy."

63 Greenstone et al., "Developing A Social Cost of Carbon"

${ }^{64}$ Board of Governors of the U.S. Federal Reserve System, "10-Year Treasury Inflation-Indexed Security."

65 Bauer and Rudebusch, "Interest Rates Under Falling Stars."

66 Giglio et al., "Climate Change and Long-run Discount Rates."

67 A fixed rate below 2 percent does not contradict OMB Circular A-4 when a long-lived benefit stream is under consideration: "If your rule will have important intergenerational benefits or costs you might consider a further sensitivity analysis using a lower but positive discount rate in addition to calculating net benefits using discount rates of 3 and 7 percent." See OMB, "Circular A-4."
} 
Monthly 10-year Treasury Security Interest Rates, Inflation-Adjusted

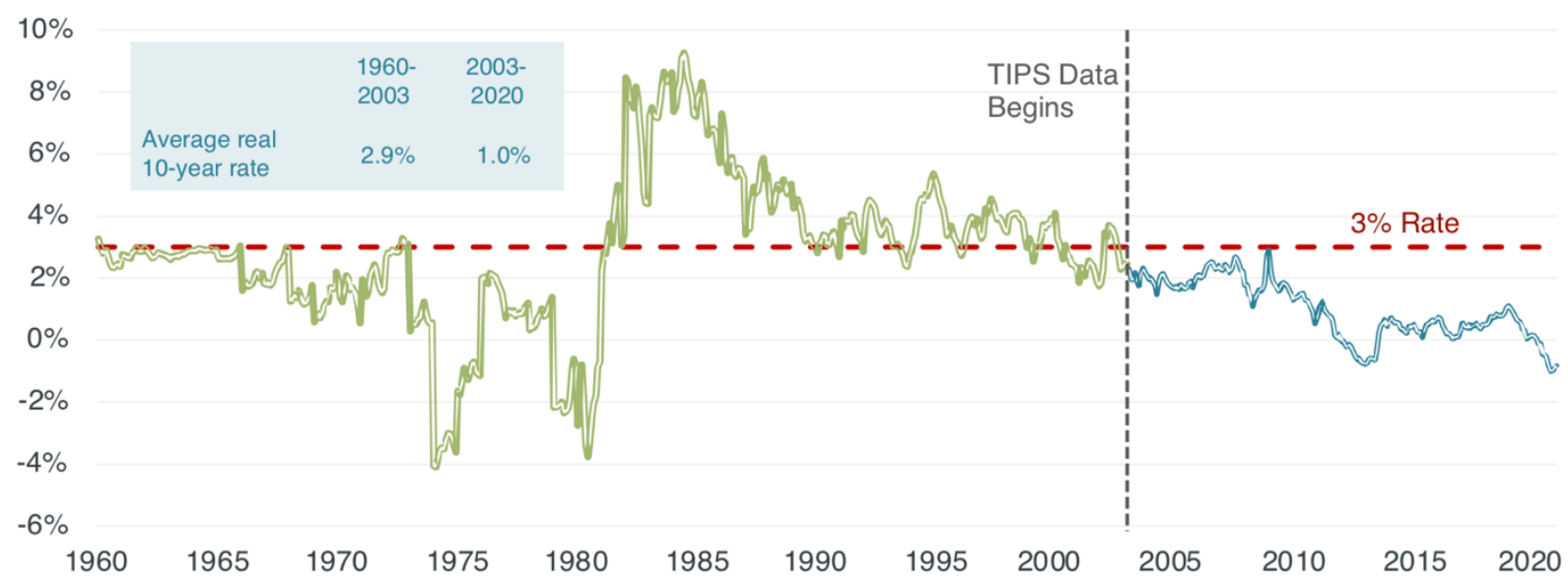

Figure 6: Monthly 10-year inflation-adjusted Treasury security interest rates. Figure shows monthly 10year Treasury security interest rates, adjusted for inflation, over the period 1960 to 2020. Nominal interest rates, TIPS, and inflation data were retrieved from the Federal Reserve Bank of St. Louis. The Treasury Inflation-Indexed Security (TIPS) rate is available starting in January 2003. Interest rates prior to 2003 are imputed by subtracting the annual inflation rate from the nominal interest rate.

There is also the possibility, however, that the riskless rate itself is not appropriate as the central discount rate due to the unique risk properties of climate change and uncertainty about future interest rates. Because discount rates reflect the returns to investments that mitigate climate change, Americans are best served by using an interest rate associated with investments that match the structure of payoffs from climate mitigation. Capital asset pricing models recommend low discount rates in scenarios where investments (in this case $\mathrm{CO}_{2}$ mitigation) pay off in "bad" states of the world - that is, if climate damages are likely to coincide with a slowing overall economic growth rate that for example could be due "tipping points" or large-scale human responses to climate change, including mass migration. ${ }^{68}$ If on the other hand climate damages act as tax on the economy (i.e., total damages are larger when the economy grows faster), then higher discount rates like the average return in equity markets would be merited.

68 Greenstone et al., "Developing A Social Cost of Carbon." 
A second potential approach to deriving a discount rate is to explicitly account for future economic growth using the so-called Ramsey equation, ${ }^{69}$ which is often referred to as the prescriptive approach. This approach has been recommended by the NAS as a "feasible and conceptually sound framework" (NAS, 2017). Rather than rely on observed interest rates, it derives a discount rate from assumptions about three parameters: the pure rate of time preference, the growth rate of consumption, and a parameter capturing the decreasing marginal utility of consumption. Values for the first and third parameters have been estimated in a large literature, while the consumption growth rate will depend on the set of socioeconomic scenarios developed in the socioeconomic and emissions module described above. ${ }^{70}$

The Ramsey approach has two key limitations. First, future economic growth is uncertain, while the Ramsey equation is deterministic. Second, climate damages are likely to be the highest in possible future scenarios where economic growth is the lowest. Both facts imply that climate mitigation policies act as a form of insurance for the future and imply a lower discount rate than is given by the Ramsey equation. Besides these limitations, some find it unappealing that the Ramsey approach requires several judgments by "experts" about the value of key parameters, rather than relying on observed market interest rates.

Recommendation: We recommend continuing to rely on existing asset markets to guide the choice of discount rates. Based on recent asset market trends, we recommend a discount rate of no higher than 2 percent.

\section{Ingredient 4: Global or Domestic Damages}

Background and 2010 IWG Approach: Traditionally, regulatory cost-benefit analyses (CBAs) have only considered the domestic benefits and costs of policies, on the theory that what matters for U.S. policy are the effects of regulations on U.S. citizens. However, unlike nearly every other environmental pollutant, $\mathrm{CO}_{2}$ emissions are

\footnotetext{
69 Ramsey, "A Mathematical Theory of Saving."

70 The Ramsey equation expresses the discount rate as $r=\delta+\eta \times g$, where $\delta$ measures the pure rate of time preference, $g$ measures the growth rate of consumption, and $\eta$ captures the decreasing marginal utility of consumption. The consensus is that $\delta$ likely ranges between zero and two. Values for $\eta$ have been estimated in a large literature, and range from one to four, but are generally centered around two (e.g., Arrow, 2007; Dasgupta, 2007, 2008; Hall, 2009; Weitzman, 2007, 2009).
} 
overwhelmingly a global problem. The damages caused by a ton of carbon emissions in the United States are felt globally. Perhaps even more importantly, the United States is harmed by emissions from abroad, so that when emissions are reduced in China, the European Union, India, and elsewhere, Americans benefit. In light of the global nature of the problem, and as a means to aid international negotiations in obtaining emissions reduction commitments abroad, the IWG chose to use global damages to calculate the SCC. In 2017, the Trump administration switched to only counting domestic damages in the calculation of the SCC.

Progress: The overwhelming consensus amongst scientific and economic experts is that the best policy is to include global damages. ${ }^{71}$ Although focusing exclusively on the domestic costs of climate change may appear to put U.S. interests first, it does not; indeed, a growing body of evidence demonstrates the opposite. Nearly 90 percent of global emissions take place outside the United States, and since the climate does not differentiate between a ton of carbon emitted in New York and a ton emitted in Beijing, the United States will never be able to protect its citizens from climate change without negotiating emissions reductions from other countries. If every nation uses a domestic figure, all nations will lose; a global figure is necessary to overcome what might be seen as a classic prisoner's dilemma. ${ }^{72}$

Importantly, history shows us that when the United States accounts for the full global cost of climate change it incentivizes other countries to reduce their own emissions, which ultimately benefits the United States more than any purely domestic climate policy could. As noted above, some nations simply borrowed the U.S. SCC. And in some cases, the use of a global SCC, by the United States, plausibly contributed to international action. For example, in 2014 the U.S. EPA proposed the Clean Power Plan, and within four months the United States extracted a promise from China to make significant reductions in its own emissions. ${ }^{73}$ Altogether, it is estimated that the United States was able to leverage 6.1-6.8 tons of $\mathrm{CO}_{2}$ reductions from other countries for every ton that it pledged to cut in the Paris Climate Agreement. ${ }^{74}$ The global SCC - that is, an SCC informed by global damages, not just domestic - is an ingredient in efforts to procure the necessary international action.

\footnotetext{
71 NAS, "Valuing Climate Damages."

${ }^{72}$ For relevant discussion, see Kotchen, "Which Social Cost of Carbon?"

${ }^{73}$ Greenstone, "United States House Committee."

${ }^{74}$ Houser, "Calculating the Climate Reciprocity Ratio."
} 
Though for many regulations it is standard to use only domestic measures of costs and benefits, on the grounds that what matters are the effects of regulations on U.S. citizens, that should not be the case with the social cost of carbon. Indeed, the use of the domestic measure for the SCC could actually harm U.S. citizens. What the United States does sets an example for the world. If Washington only measures the domestic impacts of its emissions, it will not only discount the effects of its actions on other countries, but also contribute to a situation in which multiple nations are allowing levels of emissions that harm their citizens. The cumulative effect of the U.S. decision could be higher emissions in many countries around the world, which would harm U.S. citizens. Even if policymakers decide that the effects of regulations on U.S. citizens are what matter (in terms of both law and policy), it would make sense to use the global measure, as it would protect U.S. citizens against a range of adverse effects from unmitigated climate change.

\section{Our recommendation is to use global damages in calculating the SCC. The United} States has a central role in global diplomacy and its leadership is necessary to protect its citizens from climate damages. To use a domestic SCC would be to abandon this role of global leadership. It would also create an incentive for other nations to do the same, creating a risk of losing out on the benefits from potential foreign emissions reductions.

\section{B. Additional Scientific Advances}

\section{Ingredient 5: Socioeconomic and Emissions Module}

Background: To calculate the SCC, it is necessary to compare a baseline trajectory of economic growth and $\mathrm{CO}_{2}$ emissions to a trajectory in which one more ton of $\mathrm{CO}_{2}$ is released. All else equal, a higher baseline $\mathrm{CO}_{2}$ emissions trajectory will result in a greater SCC, because projected climate change damages are nonlinear; that is, an additional ton of $\mathrm{CO}_{2}$ emissions is projected to cause more damages at higher atmospheric concentrations of $\mathrm{CO}_{2}$. Baseline economic growth affects the $\mathrm{SCC}$ in a variety of competing ways. Richer economies consume more energy and generate higher emissions, such that marginal tons do more damage and populations have higher willingness-to-pay to avoid climate change, which increases the SCC. That said, richer countries are better prepared to invest in adaptations - such as increased air 
conditioning - that reduce the social costs of climate change. Changing population demographics can also alter the magnitude of future climate change damages by, for example, increasing the total population and raising the share of the population at higher risk of heat-induced mortality.

2010 IWG Approach: Since future emissions and economic growth are unknown, the IWG combined a range of five possible trajectories developed by the Stanford Energy Modeling Forum (EMF-22) with crude probabilistic assumptions. Four of these scenarios represent business-as-usual (BAU) trajectories, while the last assumes that aggressive climate policies dramatically reduce future emissions. The IWG calculated the SCC under all five scenarios and averaged the result, giving equal weight to each scenario.

Progress: In the past ten years, there has been only modest scientific progress in developing baseline scenarios due to the stubborn difficulties in making long-run population and economic growth projections. The IPCC and many researchers have moved towards using the Shared Socioeconomic Pathways (SSPs, built collaboratively by a group of climate researchers over the last several years) as benchmark scenarios. The SSPs may be a worthwhile update over the EMF-22 pathways, as the latter undersample possible future scenarios. ${ }^{75}$ Moreover, the SSPs can be linked to the Representative Concentration Pathway (RCP) emissions scenarios, a standardized set of emissions trajectories used widely across the climate modeling community. ${ }^{76}$

However, while the range of different modeling groups generating SSP and RCP scenarios captures some degree of model and parameter uncertainty, these scenarios do not systematically characterize uncertainty in emissions or socioeconomic projections. In recent years, economists have developed ${ }^{77}$ more sophisticated modeling techniques that rely on historical data to generate probabilistic ${ }^{78}$ economic projections and demographers have done the same for population ${ }^{79}$. An alternative is to rely on expert elicitation techniques, that is, a process by which researchers synthesize the informed opinion of experts. The weakness of this technique is that it relies on a potentially

\footnotetext{
75 O’Neill, "Multi-Century Scenario Development;" Kopp and Mignone, "The U.S. Government's Social Cost of Carbon Estimates."

${ }^{76}$ Riahi et al., "The Shared Socioeconomic Pathways."

77 See, for example, Müller et al., "An Econometric Model of International Long-run Growth Dynamics"

${ }^{78}$ Probabilistic projections describe the likelihood of experiencing a particular future condition. A weather forecast warning of a 30 percent chance of rain tomorrow, for example, is a probabilistic projection.

${ }^{79}$ United Nations, "World Population Prospects 2019: Highlights."
} 
unrepresentative sample of experts' subjective judgments, while its strength is that those individuals may add information that is not captured by existing statistical approaches. As outlined by the NAS, empirically based projections can be combined with expert elicitation to formulate new socioeconomic and emissions projections that represent the many sources of uncertainty involved in generating long-run forecasts. ${ }^{80}$

\section{Recommendation: To generate socioeconomic and emissions projections, our} recommendation is to rely either on a combination of the SSPs and the RCPs or on new probabilistic projections that combine statistical methods with expert elicitation. The probabilities assigned to each projection should be chosen to best represent the most likely future global pathway.

\section{Ingredient 6: Valuing Uncertainty about Climate Risk}

Background and $2010 \mathrm{IWG}$ : There are several sources of uncertainty in the calculation of the SCC. These include uncertainty about future economic growth, the sensitivity of the global climate to additional emissions, and the economic damages for a given level of climate change. Economic theory and empirical evidence (see, for instance, the general existence of the insurance industry) reveal that people dislike risk and are willing to pay to reduce their exposure to it. The IWG chose not to account for uncertainty in valuing climate damages but noted that this decision "demands further attention." 81

Progress: Economic theory and empirical research decisively support the idea that people are risk-averse and value reducing uncertainty. In the last decade, advances in computing have enabled probabilistic climate change projections that capture multiple measures of uncertainty about the magnitude of climate damages. Thus, for the first time, it is possible to characterize these uncertainties and to incorporate them into the calculation of the SCC. For example, one recent study provided estimates of the total change in energy expenditures under climate change, accounting for both statistical and climatological uncertainty. ${ }^{82}$ Two other recent studies provide the analogous information for mortality ${ }^{83}$ and labor supply ${ }^{84}$. A large theoretical literature demonstrates that

\footnotetext{
80 NAS, "Valuing Climate Damages."

81 Greenstone et. al, "Developing a Social Cost of Carbon."

${ }^{82}$ Rode et al., "Estimating a Social Cost of Carbon for Global Energy Consumption."

83 Carleton et al., "Valuing the Global Mortality Consequences of Climate Change."

${ }^{84}$ Rode et al., "Labor Supply in a Warmer World."
} 
accounting for this uncertainty when individuals are modeled as risk averse can substantially increase the SCC. ${ }^{85}$ Although these methods have not yet been applied to new empirically derived probabilistic damage estimates, it would be straightforward to do so. ${ }^{86}$

\section{We recommend that the calculation of the SCC account for the considerable uncertainty from multiple sources about damages using standard economic tools for valuing this uncertainty. 87}

\section{Ingredient 7: Equity}

Background: An additional dollar is worth more to a poor person than a wealthy one. Applying this principle to the SCC would require "equity weighting" within the United States such that a given amount of climate damages projected to occur in poorer counties or states of the United States contribute more to the SCC than equal damages that occur in wealthier regions. Indeed, this idea is the basis for the environmental justice movement in the United States. Taken one step further, this logic would mean that damages occurring in poor countries are weighted more highly than damages in wealthy countries.

2010 IWG Approach: The IWG chose to omit equity weighting in its analysis, citing theoretical and practical concerns. Theoretically, the IWG determined the economic literature on equity weighting was insufficiently mature. Practically, the IWG determined that standard operating procedure for the U.S. government required separate distributional analyses of policies, rather than incorporating distributional concerns into cost-benefit analyses. ${ }^{88}$

\footnotetext{
${ }^{85}$ See, for example, Lemoine, "The Climate Risk Premium;" Jensen and Traeger, "Pricing Climate Risk;" Jensen and Traeger, "Optimal Climate Change Mitigation Under Long-term Growth Uncertainty;" Traeger, "Analytic integrated assessment and uncertainty."

86 The application of standard methods of uncertainty valuation to empirically derived probabilistic damage estimates is a central feature of Pathway "C", one of the recommended pathways for development of a new SCC described below.

${ }^{87}$ Specifically, this should be done by accounting for risk aversion using standard parameterizations of the shape of the utility function (e.g., $\eta=2$ ) from the existing literature to determine the "certaintyequivalent" value of damages under climate change (Traeger, "Why Uncertainty Matters"). A "certaintyequivalent" value is computed by determining the consumption loss that society would accept as a certain outcome in place of the distribution of future uncertain outcomes.

${ }^{88}$ Greenstone et al., "Developing a Social Cost of Carbon."
} 
Progress: The same logic that justifies discounting and the valuation of uncertainty over future states of the world implies that equity weights should be applied in any SCC calculation; declining marginal value of consumption is the fundamental economic concept behind all three concerns. Therefore, the most intellectually coherent approach to treating equity would be to calibrate equity weights from the large literature studying the marginal value of consumption, and to apply these weights at the spatial resolution of damages. ${ }^{89}$

However, OMB Circular A-4, ${ }^{90}$ which guides cost benefit analysis across the U.S. government, has not been altered since its release and does not clearly allow for equity weighting within cost benefit calculations. Therefore, conducting equity weighting would represent a significant departure from standard U.S. cost benefit analysis. Further, it would have significant precedential implications far beyond climate regulations and environmental policy.

Though we believe there is a strong theoretical and empirical case for equity weighting, we recommend that it not be incorporated into the SCC until there is an overhaul of Circular A-4. Such a review would allow for a full consideration of the implications across multiple domains.

\section{Three Pathways Toward an Updated SCC}

Of the four ingredients that are essential to update in a new SCC, only two can be immediately implemented by the Biden administration upon inauguration: changes to the discount rate and the inclusion of global damages. A holistic update to the SCC that integrates substantial scientific progress in the other two essential ingredients - the climate model and damage function - will involve reconvening the Inter-agency Working Group (IWG) to assess the costs and benefits of three distinct possible implementation pathways:

- Pathway A: Update the original IAMs (as much as possible)

\footnotetext{
${ }^{89}$ Standard parameterizations of utility function curvature (e.g., $\eta=2$ ) can be used to calibrate equity weights.

${ }^{90}$ OMB, "Circular A-4."
} 
- Pathway B: Build a new IAM (under the current Circular A-4)

- Pathway C: Build a new IAM (under an updated Circular A-4)

Each of these pathways will require an integration of research components that would entail several months of work.

We recommend that the Biden administration immediately update the SCC by returning to the 2013 IWG's approach, applying a 2 percent discount rate to reflect the profound changes in global capital markets in recent years. Simultaneously, we recommend that the Biden administration should reconvene the IWG to conduct a more holistic update, following Pathway B. While the IWG should consider the pros and cons of all three pathways for a comprehensive SCC update, we believe Pathway B is the most feasible, transparent, and accommodating of evolving scientific research (Figure 7). If Circular A-4 were to be updated in the future, we believe that Pathway C should be given careful consideration for adoption by a new IWG.

Regardless of which path the Biden administration chooses, it is imperative that a new SCC incorporate an updated climate model, a new set of damage functions, a lower discount rate, and global damages. These four essential changes will ensure that the U.S. SCC is once again near the frontier of understanding in a rapidly evolving area and in so doing will best serve the American people. Updates to the other three SCC ingredients would be valuable, but our view is that they are generally judgment calls that turn on several factors including scientific and/or economic evidence and political considerations like precedential effects on regulatory policy in other domains. Among these three other ingredients, however, we think there is an especially strong case for valuing the substantial uncertainty around climate damages.

The following sections describe the potential pathways for a holistic update to the SCC. 


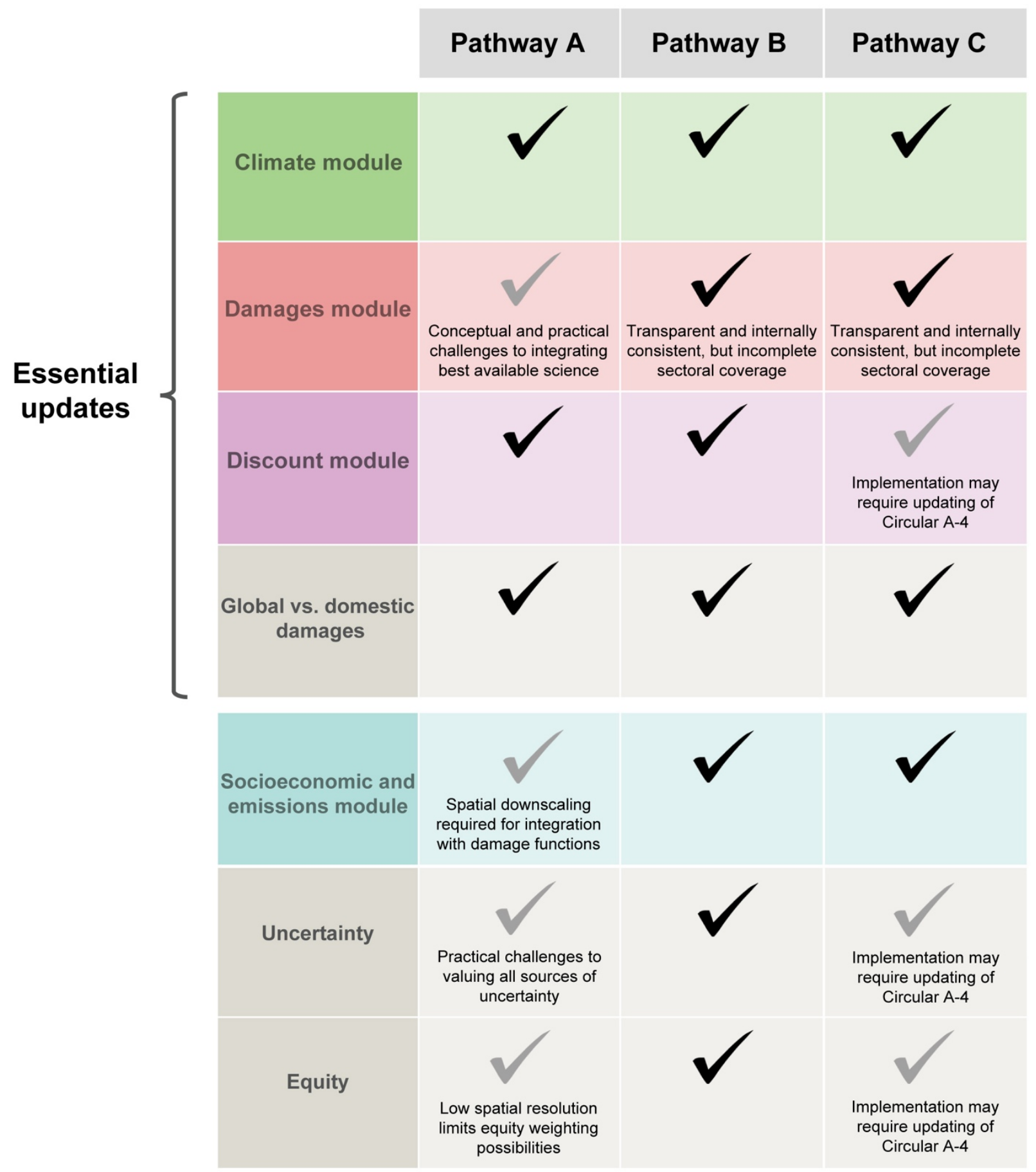

Figure 7: Three pathways toward an SCC that updates all seven ingredients. Figure uses checkmarks to indicate whether bringing each SCC ingredient to the current scientific frontier is feasible within each of three possible pathways for a new SCC framework. Black checkmarks indicate a feasible update, while grey checkmarks indicate substantial implementation challenges. See text for a detailed discussion of each pathway. 


\section{Pathway A: Update Existing IAMs as Much as Possible}

The first SCC updating pathway closely mimics the structure used by the IWG in its original SCC calculation. This requires wherever possible updating each of the seven SCC ingredients within the three IAMs. One would then run each of the updated versions of these three models and produce new distributions of SCCs. An appeal of this pathway is that it is relatively straightforward to replace the existing climate models in each IAM with the FAIR model, including the construction of a semi-empirical model of global mean sea level rise. Moreover, this approach may be attractive because the Biden administration could rely on the original IAM model parameters when updated scientific evidence is not available or cannot objectively inform a key modeling decision. ${ }^{91}$

The Achilles heel of Pathway A is that while the ultimate goal of the exercise is to estimate the damages from an additional ton of $\mathrm{CO}_{2}$, there is not a compelling way to base this estimate on the latest evidence on climate change damages under this pathway. The challenges are both conceptual and practical.

On the conceptual side, it is not straightforward to replace the existing damage functions with improved damage functions for any of the three IAMs. In the case of FUND, it is possible to subdivide the overall damage function into sector-specific functions that can roughly be mapped to the existing improved sectoral damage functions. ${ }^{92}$ But the result would be an imperfect melding of new, scientifically robust analysis with older modeling assumptions that are only loosely tied to empirical evidence. The challenge of replacing the damage functions in DICE and PAGE is even greater, because their overall damage functions cannot readily be subdivided into categories that map to the empirically founded sectoral damage functions. The best case is that there would be some risk of double counting and then a mixing of the newer empirically founded and the older assumption-driven approaches with unclear weightings between the two. Overall, there is not a clear correspondence between

\footnotetext{
${ }^{91}$ For example, some key sectors have insufficient empirical evidence for damage function calibration (e.g., ecosystem services, vector-borne disease). Similarly, evidence on the climatological likelihood and socioeconomic impact of tipping points such as ice sheet melt, breakdown of ocean currents, or release of methane from the permafrost are lacking.

${ }^{92}$ For example, energy demand in FUND can be mapped directly to the energy demand damage function derived in Rode et al. (2020b), while the mortality damage function empirically derived in Carleton et al. (2020) covers only some of the causes of death forming mortality-related damages in FUND.
} 
empirically founded, sector-specific damage functions and IAM damage functions, which makes combining them conceptually complicated.

On the practical side, the nature of recent damage function estimates makes it challenging to replace components of the existing IAMs' damage functions with the new, empirically founded sectoral damage functions for at least two reasons. ${ }^{93}$ First, none of the existing IAMs have sufficient spatial resolution in socioeconomic projections to align population and income trajectories with new damage functions that reflect differences in climate change impacts at the local level (e.g., county). Second, adaptation is treated very differently in each model, ${ }^{94}$ such that adjustments to incorporate real-world evidence on sector- and region-specific adaptation will require substantial changes to each model's original structure.

In addition to these challenges, it will be difficult to fully follow the recommendations above with respect to both the valuation of uncertainty (Ingredient six) and the treatment of equity (Ingredient seven). With respect to uncertainty, DICE is not designed to account for the many uncertain parameters in the SCC calculation, and FUND and PAGE can only enable valuation of uncertainty to the extent that sectorspecific damage functions and their corresponding uncertainties can be integrated into the modeling framework; as discussed above, this is not a straightforward task. If equity weighting were pursued by the Biden administration, the low spatial resolution of all IAMs limits their ability to capture and value differences in the welfare effects of climate change. ${ }^{95}$

Although Pathway A is feasible and was recommended by the NAS for use in the nearterm, the integration of new, empirically founded sectoral damage functions into the

\footnotetext{
${ }^{93}$ Initial efforts to update the damage module within a single IAM (e.g., DICE, FUND) have each constituted a significant academic publication, given the challenges involved in conforming new, generally richer, information to the existing IAM frameworks. For example, Moore et al. (2017) replace the agricultural damage function in FUND using a meta-analysis of the empirical agricultural-impacts literature, and Bressler (2020) does the same by adding a mortality damage function on top of existing DICE damages.

${ }^{94}$ Diaz and Moore, "Quantifying the Economic Risks of Climate Change;" Moore et al., "New Science of Climate Change Impacts on Agriculture."

${ }^{95}$ Note that one possible solution would be to incorporate equity weighting into the aggregate damage function of each IAM by valuing welfare differences across high-resolution empirical damage estimates. This is done in Pathway C. However, this is only feasible within Pathway A to the extent that sectorspecific damage functions can be integrated into each IAM; the challenges of doing so are discussed above.
} 
existing IAMs has conceptual inconsistencies and is likely to be practically challenging. No existing implementation exists for near-term use. Thus, Pathway A is a viable option, but it cannot fully accommodate one of the key advances in understanding about climate change that have taken place in the last decade.

\section{Pathway B: Build a new IAM (under the current Circular A-4)}

The second pathway is to build a new SCC framework that fully integrates scientific advances in each of the seven SCC ingredients. This is the approach recommended for longer-term implementation by the NAS. ${ }^{96}$

As above in the case of Pathway A, such a new IAM framework is not available for immediate use. However, the Climate Impact Lab (CIL), ${ }^{97}$ of which both authors are core members, is aiming to release such a framework in the first half of 2021. The CIL combines the SSP economic and population projections, high-resolution climate projections for multiple RCP emissions scenarios, and rich historical socioeconomic and climate datasets to estimate sector-specific, flexible, globally-representative damage functions that capture heterogeneity across approximately 25,000 global regions and account for adaptation and its costs. It then applies the simple Earth system model FAIR and a wide range of valuation and discounting approaches to transform these damage functions into a full distribution of SCC estimates, accounting for multiple sources of uncertainty.

This approach has some strengths and weaknesses. A great appeal of this approach is that each of the seven ingredient recommendations can be addressed, including the four essential updates. On the other hand, this pathway's main weakness is that damage functions meeting the above criteria are not currently available for all sectors likely to be affected by climate change. Damage functions for some of these sectors are currently under development, both by the CIL and by other researchers, so this pathway will become more complete as science and economics advance. However, at least in the medium term, the resulting SCC will be based on an incomplete measure of climate

\footnotetext{
96 NAS, "Valuing Climate Damages."

97 The Climate Impact Lab is a collaboration of climate scientists, economists, computational experts, researchers, analysts, and students working to build empirically derived, local-level estimates of climate change damages and an empirically based SCC. More information on the Climate Impact Lab can be found at: http://www.impactlab.org/.
} 
damages. Although this is an important shortcoming, many of the most important areas of incomplete knowledge - such as catastrophic risks and interactions across regions and sectors - remain overly simplistic or completely absent in the IAMs themselves. ${ }^{98}$

While an initial SCC built under this pathway will be incomplete, an important strength of this approach is that it can accommodate future advances in understanding. In particular, in a new IAM built from empirical damage estimates, it is straightforward to integrate results from new studies updating sector-specific damages or providing estimates for previously unquantified sectors. Similar updates to other modules, such as the climate model, are also easily accommodated. Of course, any such revisions should be limited to changes that meet the damage function, climate model, or other corresponding criteria laid out above.

An important additional benefit of a new SCC framework built from recent empirical damage estimates is that the different effects of climate change across socioeconomic groups can be explicitly described. Recent, local-level estimates of sectoral damages have shown that climate change disproportionately affects today's poorest populations. ${ }^{99}$ An SCC framework based on such studies will enable the Biden administration to evaluate and consider the distributional effects of climate policies for localities within and beyond the United States.

Our conclusion is that scientific and economic understanding has advanced enough that a revised SCC should be fully based on empirical evidence that meets modern standards. This will best serve the interests of the American people. While this approach may initially omit certain categories of damages, existing updated SCC results suggest that even partial accounting of sector-specific damages is likely to raise the existing U.S. SCC (see Figure 1), particularly if discount rates are updated and uncertainty is properly valued. Further, we think that the SCC's political and legal durability would be enhanced by this approach, which is built to accommodate a scientific literature that will undoubtedly continue to evolve.

\footnotetext{
${ }^{98}$ Kopp and Mignone, "The U.S. Government's Social Cost of Carbon Estimates."

${ }^{99}$ See, for example, Hsiang et al., "Estimating Economic Damage From Climate Change."
} 


\section{Pathway C: Build a new IAM (under an updated Circular A-4)}

A third pathway constructs the same new SCC framework as described for Pathway B, only departing from Pathway B when valuing the sector-specific, empirically derived climate impacts that form the damage function. In particular, this approach builds a damage function that embeds discounting (Ingredient three), the valuation of uncertainty (Ingredient six), and the treatment of equity (Ingredient seven) into a single cohesive step. In so doing, this pathway directly contradicts some of the individual recommendations for these three ingredients listed above; if this pathway is taken by a future IWG, we recommend updating these ingredients as described below. All other aspects of this pathway follow Pathway B described above.

This pathway is based on the recognition that a simple economic principle - declining marginal value of consumption - underlies the motivation for discounting as well as the valuation of both equity and uncertainty. ${ }^{100}$ This principle is based on the straightforward observation that $\$ 100$ is worth more to a person living in poverty than a wealthy person. In the climate setting, declining marginal value implies that one should attach a higher value to future and present impacts of climate change when they occur to populations experiencing lower incomes. It also means that when future incomes are uncertain, one has to account for the risk of severe damages occurring when average global income is very low, and thus when the value of an additional dollar is relatively high. ${ }^{101}$

Therefore, an argument can be made for computing an SCC in which the damage function represents the difference in the "certainty-equivalent" value of consumption across all years, populations, and possible future states of the world with and without climate change. ${ }^{102}$ In this approach, the valuation of climate damages is conducted from the perspective of a person who does not know their circumstances in advance, so they account for all potential income levels (e.g., whether they earn $\$ 25,000$ or $\$ 250,000$

\footnotetext{
100 Anthoff et al., "Discounting for Climate Change."

101 Jensen and Traeger, "Optimal Climate Change Mitigation."

102 A "certainty-equivalent" value is computed by determining the consumption loss that society would accept as a certain outcome (e.g., a certain future income growth) in place of the distribution of future uncertain outcomes (e.g., a set of likelihoods for different future incomes). In other words, it is an indicator of what people are willing to sacrifice in service of more equitable outcomes. This approach is similar in spirit to John Rawls' "veil of ignorance" thought experiment, in which an individual makes decisions about social policy without knowing who in that society they will be (Rawls, 1971).
} 
annually) and degrees of climate risk they might face (e.g., whether they live in Miami or Minneapolis). This calculation can be limited to those living in a particular country or applied to those living in any country.

Under this approach, discounting, uncertainty valuation, and accounting for equity implications are all incorporated into the construction of a single, certainty-equivalent damage function. ${ }^{103}$ To compute this damage function, estimates of possible local-level climate change damages and their associated probabilities are combined with evidence on how the marginal value of consumption declines as people become wealthier. ${ }^{104}$ Such a calculation is possible only with updated damage estimates from the recent scientific literature, which can show effects down to the local level and fully capture economic, statistical, and climatological uncertainty. A paper implementing this pathway will be released by the CIL team in 2021. ${ }^{105}$

The appeal of this approach is that it is the most intellectually coherent method for valuing the damages from climate change. However, it is not entirely clear that pursuing Pathway $\mathrm{C}$ would be consistent with Circular A-4; therefore, doing so would likely have implications for policies beyond climate and environmental regulation.

We therefore recommend Pathway B, which is the approach that will deliver a transparent, internally consistent, and scientifically robust set of SCC estimates that can accommodate evolving research and be implemented within the current legal framework. However, we believe that Pathway $\mathrm{C}$ should be carefully considered for adoption in the medium term.

\section{Conclusion}

This paper details a recipe to return the SCC to the frontier of climate science and economics. There are seven key ingredients in this recipe. The paper outlines

\footnotetext{
103 A similar certainty-equivalent welfare metric was analogously derived in Jones and Klenow (2016) to compare well-being across countries in historical data.

104 Only a single utility function parameter, $\eta$, is needed, as long as a standard constant relative risk aversion utility function is employed. A large literature generally estimates that $\eta$ is approximately equal to 2 (e.g., Arrow, 2007; Dasgupta, 2007, 2008; Weitzman, 2007, 2009).

105 Nath et al., "Estimating an Empirically Founded Social Cost of Carbon."
} 
recommendations for each of them, along with recommendations for how to pull them together to update the SCC.

We propose a two-step process that will return a seriousness of purpose to U.S. climate policy that the climate challenge demands. The first step involves an immediate update to the SCC that returns to the original IWG approach. Specifically, we propose that damage estimates again include global damages and that the 3 percent central discount rate be replaced with a 2 percent discount rate (left panel of Figure 8 ). These changes produce an SCC of $\$ 125$ in 2020 . The second step is to reconvene the IWG to conduct a comprehensive update by building a new SCC framework (right panel of Figure 8).

Following this recipe means that the SCC would reflect the substantial changes in understanding about climate change that have emerged over the last decade. Further, we believe that it would best serve the interests of the American people.

\section{Summary of Recommendations}
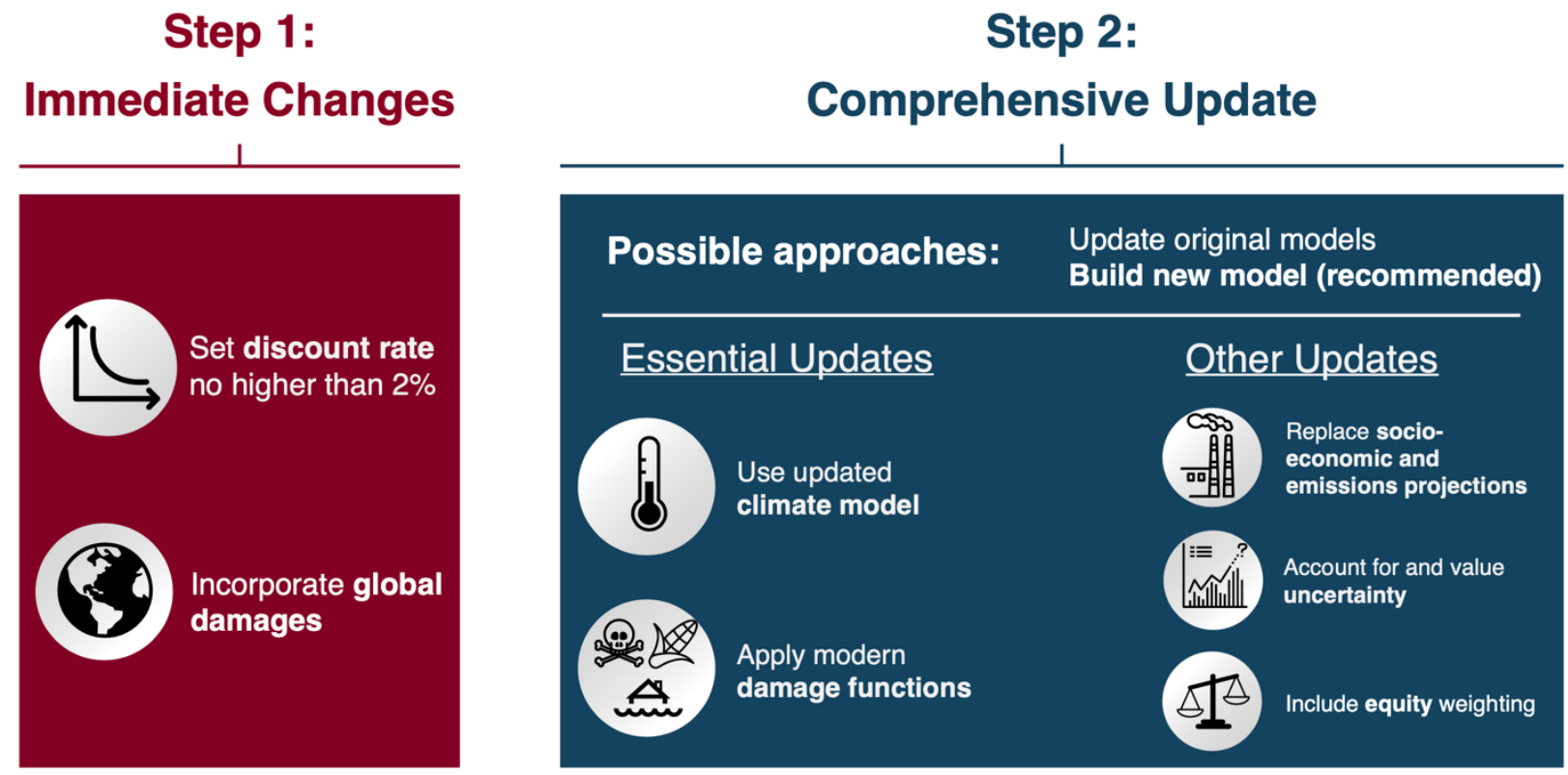

Figure 8: Summary of the recommendations made under a two-step process for updating the U.S.

government's Social Cost of Carbon. Step 1 can be implemented immediately, while Step 2 requires a new IWG conduct a holistic update to the SCC framework. 


\section{References}

Anthoff, David, Richard Plevin, Cora Kingdon, and Lisa Rennels. Mimi. Resources for the Future, September 10, 2020. https://www.mimiframework.org/.

Anthoff, David, Richard S.J. Tol, and Gary Yohe. "Discounting for Climate Change." Economics: The Open-Access, Open-Assessment E-Journal 3 (2009).

Anthoff, David, and Richard S.J. Tol. "The Income Elasticity of the Impact of Climate Change." Is the Environment a Luxury (2014): 34-47.

Arrow, Kenneth J. "Global Climate Change: a Challenge to Policy." The Economists' Voice 4, no. 3 (2007).

Auffhammer, Maximilian. "Climate Adaptive Response Estimation: Short and Long Run Impacts of Climate Change on Residential Electricity and Natural Gas Consumption Using Big Data." No. w24397. National Bureau of Economic Research, (2018).

Bauer, Michael D., and Glenn D. Rudebusch. "Interest Rates Under Falling Stars." American Economic Review 110, no. 5 (2020): 1316-54.

Board of Governors of the U.S. Federal Reserve System. "10-Year Treasury InflationIndexed Security, Constant Maturity [DFII10]." FRED: Federal Reserve Bank of St. Louis, (2020). https://fred.stlouisfed.org/series/DFII10.

Bressler, R. Daniel. "The Mortality Cost of Carbon." CEEP Working Paper Series, (2020).

Burke, Marshall, Solomon M. Hsiang, and Edward Miguel. "Global Non-linear Effect of Temperature on Economic Production." Nature 527, no. 7577 (2015): 235-239.

Burke, Marshall, and Vincent Tanutama. "Climatic Constraints on Aggregate Economic Output." No. w25779. National Bureau of Economic Research, (2019).

Cai, Ruohong, Shuaizhang Feng, Michael Oppenheimer, and Mariola Pytlikova. "Climate Variability and International Migration: The Importance of the Agricultural Linkage." Journal of Environmental Economics and Management 79 (2016): 135-151. 
Carleton, Tamma A., and Solomon M. Hsiang. "Social and Economic Impacts of Climate." Science 353, no. 6304 (2016).

Carleton, Tamma A., Amir Jina, Michael T. Delgado, Michael Greenstone, Trevor Houser, Solomon M. Hsiang, Andrew Hultgren et al. "Valuing the Global Mortality Consequences of Climate Change Accounting for Adaptation Costs and Benefits." No. w27599. National Bureau of Economic Research, (2020).

Cline, William R. "The Economics of Global Warming." Institute for International Economics, (1992).

Dasgupta, Partha. "The Stern Review's Economics of Climate Change." National Institute Economic Review 199, no. 1 (2007): 4-7.

Dasgupta, Partha. "Discounting Climate Change." Journal of Risk and Uncertainty 37, no. 2-3 (2008): 141-169.

Davis, Lucas W., and Paul J. Gertler. "Contribution of Air Conditioning Adoption To Future Energy Use Under Global Warming." Proceedings of the National Academy of Sciences 112, no. 19 (2015): 5962-5967.

Dell, Melissa, Benjamin F. Jones, and Benjamin A. Olken. "Temperature and Income: Reconciling New Cross-sectional and Panel Estimates." American Economic Review Papers and Proceedings 99, no. 2 (2009): 198-204.

Dell, Melissa, Benjamin F. Jones, and Benjamin A. Olken. "Temperature Shocks and Economic Growth: Evidence from the Last Half Century." American Economic Journal: Macroeconomics 4, no. 3 (2012): 66-95.

Dell, Melissa, Benjamin F. Jones, and Benjamin A. Olken. "What Do We Learn from The Weather? The New Climate-Economy Literature." Journal of Economic Literature 52, no. 3 (2014): 740-98.

Deryugina, Tatyana, and Solomon Hsiang. "The Marginal Product of Climate." No. w24072. National Bureau of Economic Research, (2017). 
Deschênes, Olivier, and Michael Greenstone. "The Economic Impacts of Climate Change: Evidence from Agricultural Output and Random Fluctuations in Weather." American Economic Review 97, no. 1 (2007): 354-385.

Deschênes, Olivier, and Michael Greenstone. "Climate Change, Mortality, and Adaptation: Evidence from Annual Fluctuations in Weather in the United States." American Economic Journal: Applied Economics 3, no. 4 (2011): 152-85.

Diaz, Delavane. "Evaluating the Key Drivers of the U.S. Government's Social Cost of Carbon: A Model Diagnostic and Inter-Comparison Study of Climate Impacts in DICE, FUND, and PAGE." FUND, and PAGE (October 3, 2014) (2014).

Diaz, Delavane, and Frances Moore. "Quantifying the Economic Risks of Climate Change." Nature Climate Change 7, no. 11 (2017): 774-782.

Dietz, Simon, Rick van der Ploeg, Armon Rezai, and Frank Venmans. "Are Economists Getting Climate Dynamics Right and Does It Matter?" CESifo Working Paper No. 8122 (2020).

Durlauf, Steven N. "The Rise and Fall of Cross-Country Growth Regressions." History of Political Economy 41, no. Suppl_1 (2009): 315-333.

Gasparrini, Antonio, Yuming Guo, Masahiro Hashizume, Eric Lavigne, Antonella Zanobetti, Joel Schwartz, Aurelio Tobias et al. "Mortality Risk Attributable to High and Low Ambient Temperature: A Multicountry Observational Study." The Lancet 386, no. 9991 (2015): 369-375.

Giglio, Stefano, Matteo Maggiori, Johannes Stroebel, and Andreas Weber. "Climate Change and Long-run Discount Rates: Evidence from Real Estate." No. w21767. National Bureau of Economic Research, (2015).

Gollier, Christian, and James K. Hammitt. "The Long-Run Discount Rate Controversy." Annual Review of. Resource Economics 6, no. 1 (2014): 273-295. 
Greenstone, Michael, Elizabeth Kopits, and Ann Wolverton. "Developing A Social Cost of Carbon for U.S. Regulatory Analysis: A Methodology and Interpretation." Review of Environmental Economics and Policy 7, no. 1 (2013): 23-46.

Greenstone, Michael. Congressional Testimony. "United States House Committee on Oversight and Reform, Subcommittee on Environment, Hearing on 'Economics of Climate Change"' (2019).

Hall, Robert E. "Reconciling Cyclical Movements in the Marginal Value of Time and the Marginal Product of Labor." Journal of Political Economy 117, no. 2 (2009): 281-323.

Heutel, Garth, Nolan H. Miller, and David Molitor. "Adaptation and the Mortality Effects of Temperature Across U.S. Climate Regions." No. w23271. National Bureau of Economic Research, (2017).

Hope, Chris. "The PAGE09 Integrated Assessment Model: A Technical Description" Cambridge

Judge Business School Working Paper, (2011).

Houser, Trevor, et al. "Calculating the Climate Reciprocity Ratio". (2021).

Hsiang, Solomon, Robert Kopp, Amir Jina, James Rising, Michael Delgado, Shashank Mohan, D. J. Rasmussen et al. "Estimating Economic Damage from Climate Change in the United States." Science 356, no. 6345 (2017): 1362-1369.

Hultgren, Andrew, Tamma Carleton, Michael Delgado, Diana Gergel, Michael Greenstone, Trevor Houser, Solomon Hsiang, et al. "The Impacts of Climate Change on Global Grain Production Accounting for Adaptation." Working Paper, (2020).

Institute for Policy Integrity. "The Cost of Carbon Pollution," (2020). https://costofcarbon.org/.

Interagency Working Group on Social Cost of Carbon. "Technical Support Document: -Social Cost of Carbon for Regulatory Impact Analysis -Under Executive Order 12866." (2010). 
—. "Technical Support Document: Social Cost of Carbon for Regulatory Impact Analysis Under Executive Order 12866." (2013).

—. "Technical Support Document: Technical Update of the Social Cost of Carbon for Regulatory Impact Analysis Under Executive Order 12866." (2016).

Jensen, Svenn, and Christian P. Traeger. "Pricing Climate Risk." Working paper (2016).

Jensen, Svenn, and Christian P. Traeger. "Optimal Climate Change Mitigation Under Long-term Growth Uncertainty: Stochastic Integrated Assessment and Analytic Findings." European Economic Review 69 (2014): 104-125.

Kalkuhl, Matthias, and Leonie Wenz. "The Impact of Climate Conditions on Economic Production. Evidence from a Global Panel of Regions." Journal of Environmental Economics and Management 103 (2020): 102360.

Klenow, Peter J., and Andres Rodriguez-Clare. "Externalities and Growth." Handbook of Economic Growth 1 (2005): 817-861.

Kopp, Robert E., and Bryan K. Mignone. "The U.S. Government's Social Cost of Carbon Estimates After Their First Two Years: Pathways For Improvement." Economics: The Open-Access, Open-Assessment E-Journal 6 (2012).

Kopp, Robert E., Andrew C. Kemp, Klaus Bittermann, Benjamin P. Horton, Jeffrey P. Donnelly, W. Roland Gehrels, Carling C. Hay, Jerry X. Mitrovica, Eric D. Morrow, and Stefan Rahmstorf. "Temperature-Driven Global Sea-level Variability in the Common Era." Proceedings of the National Academy of Sciences 113, no. 11 (2016): E1434E1441.

Kotchen, Matthew J. "Which Social Cost of Carbon? A Theoretical Perspective." Journal of the Association of Environmental and Resource Economists 5, no. 3 (2018): 673-694.

Lemoine, Derek. "The Climate Risk Premium: How Uncertainty Affects the Social Cost of Carbon." University of Arizona Department of Economics Working Paper (2017): 1501. 
Livermore, Michael A., and Richard L. Revesz. Reviving Rationality: Saving CostBenefit Analysis for the Sake of the Environment and Our Health. Oxford University Press, USA, 2020.

Martens, Willem JM. "Climate Change, Thermal Stress and Mortality Changes." Social Science 83 Medicine 46, no. 3 (1998): 331-344.

Mattauch, Linus, H Damon Matthews, Richard Millar, Armon Rezai, Susan Solomon, and Frank Venmans, "Steering the Climate System: Comment," American Economic Review, (2020), 110 (4), 1231-1237.

Millar, R.J., Nicholls, Z.R., Friedlingstein, P., and Allen, M.R. "A Modified ImpulseResponse Representation of the Global Response to Carbon Dioxide Emissions." Atmospheric Chemistry and Physics, (2016).1-20.

Moore, Frances C., Uris Baldos, Thomas Hertel, and Delavane Diaz. "New Science of Climate Change Impacts on Agriculture Implies Higher Social Cost of Carbon." Nature Communications 8, no. 1 (2017): 1-9.

Moore, Frances C., James Rising, Niklas Lollo, Cecilia Springer, Valeri Vasquez, Alex Dolginow, Chris Hope, and David Anthoff. "Mimi-PAGE, An Open-Source Implementation of the PAGE09 Integrated Assessment Model." Scientific Data 5 (2018): 180-187.

Müller, Ulrich K., James H. Stock, and Mark W. Watson. "An Econometric Model of International Long-run Growth Dynamics." No. w26593. National Bureau of Economic Research, (2019).

NAS (National Academies of Sciences, Engineering, and Medicine). "Valuing Climate Damages: Updating Estimation of the Social Cost of Carbon Dioxide." National Academies Press, (2017).

Nath, Ishan, and members of the Climate Impact Lab. "Estimating an Empirically Founded Social Cost of Carbon," In prep. (2020).

New York State Department of Environmental Conservation. "Establishing a Value of Carbon: Guidelines for Use by State Agencies." (2020). 
New York State Energy Research and Development and Resources for the Future.

"Estimating the Value of Carbon: Two Approaches." (2020).

Nordhaus, William D. 'The 'DICE' Model: Background and Structure of a Dynamic Integrated Climate-economy Model of the Economics of Global Warming." No. 1009. Cowles Foundation for Research in Economics, Yale University, (1992).

Nordhaus, William D. "Economic Aspects of Global Warming in a Post-Copenhagen Environment." Proceedings of the National Academy of Sciences (2010) 107(26): 1172111726.

Nordhaus, William D. "Revisiting the Social Cost of Carbon." Proceedings of the National Academy of Sciences 114, no. 7 (2017): 1518-1523.

Nordhaus, William D., and Andrew Moffat. "A Survey of Global Impacts of Climate Change: Replication, Survey Methods, and a Statistical Analysis." No. w23646. National Bureau of Economic Research, (2017).

O’Neill, B. "Multi-century Scenario Development and Socioeconomic Uncertainty. In Improving the Assessment and Valuation of Climate Change Impacts for Policy and Regulatory Analysis: Modeling Climate Change Impacts and Associated Economic Damages." U.S. Environmental Protection Agency and U.S. Department of Energy. (2010).

Pindyck, Robert S. "Climate Change Policy: What Do the Models Tell Us?" Journal of Economic Literature 51, no. 3 (2013): 860-72.

Ramsey, Frank P. "A Mathematical Theory of Saving." The Economic Journal 38, no. 152 (1928): 543-559.

Rawls, John. A Theory of Justice. Harvard University Press (1971).

Riahi, Keywan, Detlef P. Van Vuuren, Elmar Kriegler, Jae Edmonds, Brian C. O’Neill, Shinichiro Fujimori, Nico Bauer et al. "The Shared Socioeconomic Pathways and Their Energy, Land Use, and Greenhouse Gas Emissions Implications: An Overview." Global Environmental Change 42 (2017): 153-168. 
Ricke, Katharine, Laurent Drouet, Ken Caldeira, and Massimo Tavoni. "Country-level Social Cost of Carbon." Nature Climate Change 8, no. 10 (2018): 895-900.

Rode, Ashwin, R. Baker, Tamma Carleton, A. D'Agostino, Michael Delgado, T. Foreman, Michael Greenstone, Trevor Houser, et al. "Labor Supply in a Warmer World: The Impact of Climate Change on the Global Workforce," Working paper, (2020a).

Rode, Ashwin, Tamma Carleton, Michael Delgado, Michael Greenstone, Trevor Houser, Solomon Hsiang, Amir Jina, et al. "Estimating a Social Cost of Carbon for Global Energy Consumption," Working paper, (2020b).

Schlenker, Wolfram, and Michael J. Roberts. "Nonlinear Temperature Effects Indicate Severe Damages To Us Crop Yields Under Climate Change." Proceedings of the National Academy of Sciences 106, no. 37 (2009): 15594-15598.

Sunstein, Cass R. "Watch for Biden Decision on Unsung Climate Metric." Bloomberg, November 10, 2020. https://www.bloomberg.com/opinion/articles/2020-11-10/bidenclimate-change-policy-turns-on-carbon-cost-calculation.

Tol, Richard S.J. "Estimates of the Damage Costs of Climate Change. Part 1:

Benchmark Estimates." Environmental and Resource Economics 21, no. 1 (2002): 47-73.

Traeger, Christian P. "Analytic Integrated Assessment and Uncertainty." Available at SSRN 2667972 (2015).

Traeger, Christian P. "Why Uncertainty Matters: Discounting Under Intertemporal Risk Aversion and Ambiguity." Economic Theory 56, no. 3 (2014): 627-664.

United Nations, Department of Economic and Social Affairs, Population Division (2019). "World Population Prospects 2019: Highlights." ST/ESA/SER.A/423.

U.S. Environmental Protection Agency and National Highway Traffic Safety Administration. "Final Regulatory Impact Analysis - The Safer Affordable Fuel-Efficient 
(SAFE) Vehicles Rule for Model Year 2021 - 2026 Passenger Cars and Light Trucks." (2020).

U.S. Government Accountability Office. "Social Cost of Carbon: Identifying a Federal Entity to Address the National Academies' Recommendations Could Strengthen Regulatory Analysis." (2020).

U.S. Office of Management and Budget. "Circular A-4: Regulatory Analysis." (2003).

Warren, Rachel, Chris Hope, Michael Mastrandrea, Richard Tol, Neil Adger, and Irene Lorenzoni. "Spotlighting Impacts Functions in Integrated Assessment." Tyndall Centre on Climate Change Working Paper 91 (2006).

Weitzman, Martin L. "A Review of the Stern Review on the Economics of Climate Change." Journal of Economic Literature 45, no. 3 (2007): 703-724.

Weitzman, Martin L. "On Modeling and Interpreting the Economics of Catastrophic Climate Change." The Review of Economics and Statistics 91, no. 1 (2009): 1-19. 